\title{
REVIEW OF THE CONIOPTERYGIDAE (NEUROPTERA) OF NORTH AMERICA WITH A REVISION OF THE GENUS ALEUROPTERYX ${ }^{1}$
}

\author{
BY VICTOR JOHNSON ${ }^{2}$
}

\section{INTRODUCTION AND REVIEW OF LITERATURE}

The smallest members of the Neuroptera belong to the family Coniopterygidae, which has several characteristics unusual within the order. The wings have reduced venation with few cross-veins and without the terminal branching of longitudinal veins found in other families. Coniopterygids produce a characteristic waxy secretion from wax glands on the head, thorax and abdomen which gives them their common name "dusty-wings"; no other neuropterans produce wax. Another unusual feature is the presence of a sclerotized penis in several genera and species. The only other neuropterans with a sclerotized penis are some species of Mantispidae (Tjeder 1956).

The first major U.S. work on this group was a Nearctic revision by Banks (1906) who reported seven U.S. species and provided a key to genera based on wing venation. Because wing venation is not always bilaterally symmetrical, a single specimen may key out to different genera depending upon the wing used. The family remained in a state of confusion until Meinander (1972) published his world revision, in which he described 22 new species from North America. He described an additional nine species in 1974 and four more in 1975. Henry (1974) recorded the introduction and establishment of Aleuropteryx juniperi $\mathrm{Ohm}$ from Europe into the eastern part of the United States. Johnson (1976) described the genus

\footnotetext{
${ }^{1}$ This paper (No. 80-7-205) is published with the approval of the Director of the Kentucky Agricultural Experiment Station and is based on research performed in partial fulfillment of the requirements for the Ph.D. degree in Entomology.

${ }^{2}$ Former research associate in the Department of Entomology, University of Kentucky, Lexington, Kentucky 40546. Present address: USDA-APHIS-PPQ, Box 182729, Erlanger, Kentucky 41018.

To simplify information in this publication, trade names of some products are used. No endorsement is intended, nor is criticism implied of similar products not named.

Manuscript received by the editor February 2, 1981.
} 
Bidesmida with one species (B. morrisoni) bringing the total to 40 species in 8 genera. This present study describes 5 additional new species. There is little doubt that there are many more undescribed species in North America.

Coniopterygids have been considered rare by most entomologists, mainly because of their small size, inconspicuous appearance and superficial resemblance to Psocoptera and Aleyrodidae. In addition, Withycombe (1922) stated that only the males are attracted to incandescent lights. I have found males and females only rarely attracted to incandescent lights, but both sexes are readily attracted to blacklights and the use of blacklight traps is the most efficient method of collecting adults.

Rather than being rare, many coniopterygids are quite common. Several species can be easily collected in numbers in the southern part of the United States where they appear to be widely and uniformly distributed. I have noted large numbers of Semidalis vicina (Hagen) congregating on oak and maple shrubbery in Kentucky, Tennessee and Arkansas and have seen this species and several others in large numbers in Texas feeding on an unidentified aphid on hackberry. Withycombe (1923) considered several coniopterygids to be "exceedingly common, at least in England...". He found Conwentzia sp. to be one of the "commonest insects in London parks" on Quercus and Platanus with Semidalis sp. and Coniopteryx sp. frequently plentiful.

The life histories of very few of the Coniopterygidae are known. Withycombe (1923) made a major contribution with studies of several species in England, Muma (1967) studied S. vicina in Florida and Henry (1976) reported on $A$. juniperi in Pennsylvania. Other studies have been made but these frequently include ambiguous species identification.

Both larvae and adults of coniopterygids are predaceous and several have been studied as biological control agents. Muma (1967) evaluated $S$. vicina for control of mites on citrus. He found this species to have several characteristics which made it suitable for biological control of citrus pests: wide distribution, stable mean population and wide food tolerance range, including rust mites, spider mites, whiteflies and scale insects. Individuals were found to consume 29-83 citrus red mites (eggs, larvae, and pupae) per day of development. Quayle (1912) reported Conwentzia hageni Banks (Conwentzia california Meinander) to be one of the commonest 
enemies of spider mites in Southern California citrus, consuming 6-15 mites per day of development. Collyer (1951) reported $C$. pineticola Enderlein to consume 15-40 mites per day. Arrow (1917) found Conwentzia psociformis Curtis to feed on Phylloxera sp. on oak, attacking all stages with "great voracity". Withycombe (1924) found that the main check on populations of Phylloxera punctata Light in England was $C$. psociformis. Henry (1976) stated that $A$. juniperi preys on two species of scale insects: juniper scale, Carulaspis juniperi (Bouche) and the minute cypress scale, Carulaspis minima (Targioni-Tozetti). Ward (1970) also reported this species feeding on $C$. juniperi in Great Britain.

In addition to feeding on live prey, adults have been reported to feed on other substances such as honeydew (Withycombe 1923 and Arrow 1917), scale secretions and honey water (Henry 1976).

Several parasites are reported for coniopterygids. Withycombe (1923) reported two species of Hymenoptera to parasitize cocoons of C. psociformis in Great Britain; the female of Lygocera sp. tears a small hole in the cocoons for insertion of the parasite's eggs. The parasite larvae feed on the coniopterygid pupa, then pupate and emerge from the host cocoon the following summer. Ceraphron sp. have been found to emerge from coniopterygid cocoons during July and August. Muma (1967) reported three parasites of the pupae of C. vicina: Dendrocerus conwentziae Gah., Camptoptera sp. and Cosmoccidea morilli How.

In view of their predaceous habits and potential for biological control of mites and small insects, there is a need for biological information on this group. Life histories are known for very few species and few species have correlation between males and females and between larvae and adults. This present study was undertaken to advance the taxonomic status of this very interesting group so that life history investigations might be more easily completed.

\section{Materials ANd Methods}

All specimens were examined either in glycerol or ethyl alcohol. Specimens on pins or points were treated with household cleaner, Formula $409{ }^{\circledR}$, for 2-24 hours, washed in water and then placed in glycerol. The Formula 409 softened the specimens and many times returned them to a state indistinguishable from specimens which have been stored in alcohol. 
For examination of genitalia, either the terminal abdominal segments or the entire abdomen was removed and treated with $10 \%$ $\mathrm{KOH}$ at room temperature for 2-10 hr. In some cases, specimens were placed in a cleaning sonicator for a few seconds, but this was too severe a treatment for general use. Specimens were then washed with water and placed in glycerol.

A dissecting microscope at $95 \times$ magnification was used for determination and for illustrations. A Zeiss Photomicroscope $\mathrm{II}^{\circledR}$ was used for more detailed examination at magnifications up to $400 \times$.

Illustrations were prepared freehand with the use of a counting grid mounted in one ocular of the dissecting microscope. Measurements are accurate to $.04 \mathrm{~mm}$. Illustrations are accurate to $.02 \mathrm{~mm}$.

After examination and illustration, all specimens which had been dissected for examination of genitalia and all specimens which were fragile and/or broken were placed in glycerol in genitalia vials for permanent storage. All other specimens were placed in vials of $80 \%$ ethyl alcohol with a few drops of glycerine.

Specimens used in this study were from the collection of the author (AUTH) or borrowed from one of the following collections: Arizona State University (ARIZ), Illinois Natural History Survey (INHS) or Utah State University (UTAH). Types were deposited in one or more of these collections or in the National Museum of Natural History (USNM). Meinander (1972) types are deposited in the California Academy of Sciences (CAS), University of California at Berkeley (UCA) or the National Museum of Natural History.

\section{Classifications and Descriptions}

Due to the recent world revision by Meinander (1972), some material which is readily available in that revision was omitted from this study. Synonomies were limited to original descriptions and to publications after 1972. In the interest of standardization, I have followed Meinander's format regarding descriptions and illustrations and have used the same terminology where possible. I have noted my differences in interpretation from Meinander. I have prepared illustrations of previously undescribed species and other species where necessary.

The descriptions include only those characters which have been found to vary within the genus. Keys are provided to the species. 
Species are discussed in alphabetical order.

Under the heading, new material examined, new country and state records are indicated by an asterisk.

\section{CONIOPTERYGIDAE Burmeister, 1839}

Coniopterygidae Burmeister, 1838:771. Type: Coniopteryx Curtis, 1834.

Eggs: Light colored, ovoid with micropylar end pointed and chorion reticulated. Incubation period varies with temperature. Withycombe (1924) reported 6-21 days for incubation.

Larvae: Spindle-shaped, generally smooth, except for rows of small setae on each abdominal segment. Head small, rounded, prognathous; slightly retracted into thorax. Eyes formed of 4-5 facets. Antennae 2 segmented. Labrum projecting, covering the mandibles completely in Coniopteryginae and partially in Aleuropteryginae. Mandibles enlarged basally, sharply pointed, slightly grooved ventrally. Maxillae pointed, with external barbs. No maxillary palpi present. Labrium reduced.

Thorax large, soft, sharply marked off from abdomen. Three segments subequal. Legs well developed, long; tarsi one segmented with two simple claws and a well developed empodium. Tibia and tarsi not freely articulating.

Abdomen 10-segmented, tapering, with 10th segment adhesive.

Notes: Meinander (1972) reported the labial palpi to be 2 segmented but Withycombe (1923) reported a pair of three segmented labial palpi.

The larval stages require about 2-4 wk for development. Withycombe (1923), working with several species, and Henry (1976) working with $A$. juniperi, reported three larval instars, while Muma (1967) working with S. vicina and Quayle (1912) working with $C$. hageni reported 4 larval instars. Meinander (1972) considers the family to have 3 larval instars. I have found 3 species in 2 genera of the Coniopteryginae to have 4 larval instars. Prior to pupation, the larvae build a flat, ovoid cocoon composed of an inner and an outer layer of white silk. The silk is produced by modified malpighian tubules (Meinander 1972) connected to an eversible anal papilla (Withycombe 1924). The cocoon is similar to that produced by some spiders and the emerging adult coniopterygids have been mistakenly thought to be parasites of spiders. Withycombe (1923) stated that 
there are 2 types of development in Conwentzia in England. During the early and mid-summer, pupation takes place normally and within about 2 weeks the adults emerge; in late summer, the larvae do not pupate immediately, but overwinter as prepupae in the cocoon and pupate early in the following spring. Henry (1976) reported A. juniperi in Pennsylvania overwintering as 2 nd instar larvae and to be active during warm periods during the winter.

Pupa: Quadrate, short with the head bent forward at an angle to thorax.

Notes: Just prior to emergence, a hole is cut in the cocoon through which the adult subsequently emerges. The pupal skin is either left entirely or partially within the cocoon or the pupa emerges and then sheds the pupal skin.

Adults: Hypognathous, strongly sclerotized head capsule. Ocelli absent, compound eyes well developed and large. Antennal sclerite and antennal condyle small. Antennal sockets often with unsclerotized area of frons between them. Male antennal segments modified and broader than in females. Mandibles small; maxillae well developed with 5-segmented palpi; labium well developed with 3segmented palpi.

Prothorax short and lightly sclerotized; meso- and metathorax well developed, strongly sclerotized, with mesothorax being larger. Meso- and metathorax of some species with distinct lateral shoulder spots darker than surrounding areas.

Legs slender with 5-segmented tarsi, 4 th segment flattened. Males with clasping setae on anterior femur.

Most with 2 pairs of well-developed wings. Exceptions are some species of Helicoconis and Coniopteryx and most species of Conwentzia which have reduced metathoracic wings. Wings held rooflike over body.

Venation of fore wing: Costa (C) much reduced and visible only at base. Subcosta $(\mathrm{Sc})$ runs parallel with margin and is distally furcate; posterior branch resembles a cross-vein (Withycombe 1922). Radius ( $R$ ) in most species basally apparently crossing base of medius (M), but no actual crossing occurs. Radial sector (Rs) branches off in middle of wing. Media forked except in Coniocompsa. Basal cross-vein may be present along with radio-medial cross-vein (Aleuropteryginae have 2 radio-medial cross-veins). Cubitus $(\mathrm{Cu})$ forks near base into 2 branches. One medio-cubital cross-vein present, striking $\mathbf{M}$ on stem or posterior branch. Two 
anal veins. Costal area with 2 or fewer cross-veins. Two basal crossveins present between $\mathrm{Cu}_{2}$ and $\mathrm{A}_{1}$.

Venation of hind wing: Costa and subcosta similar to fore wing. Rs forks off near base in Aleropteryginae, more distally in Coniopteryginae; generally furcate. Radial cross-vein between $R_{1}$ and $R s$, strikes either stem of $\mathbf{R s}$ or its anterior branch. $\mathbf{M}$ forked except in Coniopteryx and some Coniocompsa. A radio-medial cross-vein present, striking anterior branch of $\mathrm{M}$ except in Coniopteryx, where $M$ is unforked. Cu forked near base. Two anal veins present. Two or fewer cross-veins in basal part of costal area.

Membrane of wings mostly clear or unicolorous, but some with markings. Marginal fringes usually present and short. Frequently a group of hairs along base of posterior margin of hind wing and along base of costa of hind wing.

Abdomen weakly sclerotized except for genitalia. Segments 1-8 of Aleuropteryginae and segments 1-7 of Coniopteryginae with spiracles. Lateral and dorsal wax glands form transverse bands. Aleuropteryginae with paired organs called plicaturae on some segments; function unknown.

Notes: Newly emerged adults are pale and do not have the characteristic waxy power on the body and wings. Within a short time, the wax is secreted in long spirals from the wax glands, primarily located on the abdomen, head and thorax. The hind femora are used to apply the wax to the wings.

The adults are normally active and run rapidly over plant surfaces. When disturbed, they either feign death or fly. Flight is fluttery and usually ends with a landing on the underside of vegetation.

Meinander (1972) treated the genitalia extensively in his revision; therefore a comprehensive study is not included here. Discussions of genitalia are included under each genus and species heading. With few exceptions, Meinander followed the interpretation and terminology of Tjeder (1970). I have followed the terminology of Meinander, although occasionally differing from his interpretation.

Mating in Coniopterygidae is apparently accomplished by either of 2 methods: Parasemidalis sp. (Withycombe 1922) and C. pineticola (Collyer 1951) mate in a staggered parallel position with the male bending the tip of the abdomen dorsally to meet the female terminalia; $A$. juniperi mate with the male and female in a tail-to-tail position (Henry 1976). I have found 4 species of the subfamily 
Coniopteryginae ( 2 in Semidalis and 2 in Conwentzia) to mate in the staggered parallel position similar to that reported by Collyer.

Eggs are laid singly on vegetation, frequently along leaf margins (Withycombe 1923) or on the underside of leaves near the midrib (Quayle 1912). Muma found S. vicina to produce 2-5 eggs daily for 16-25 days for a maximum of 266 eggs per female.

Adult longevity varies with environmental conditions. Muma (1967) found $S$. vicina adults to live about one month.

The Coniopterygidae are divided into 2 subfamilies:

Key to subfamilies

One radio-media cross-vein in middle of fore wing.

Galea one-segmented. No plicaturae on abdomen .......... Coniopteryginae Apparently two radio-medial cross-veins in middle of fore wing (either actually two radio-medial cross veins or one and $\mathrm{M}_{1+2}$ and $\mathbf{R}_{4+5}$ briefly coalesce with the part of $\mathbf{R}_{4+5}$ between the point of fusion and the stem of Rs appearing as a second cross-vein). Galea three-segmented. Plicaturae present on abdomen ............ Aleuropteryginae

Subfamily Aleuropteryginae Enderlein, 1905

Aleuropteryginae Enderlein, 1905:225. Type: Aleuropteryx Low.

Head capsule dorso-ventrally elongated in lateral view, genae long. Galea with basigalea and terminal knob.

Fore wing with 2 radio-medial cross-veins and possible basal cross-vein. $M$ has 2 setae in middle of wing, the bases of which are enlarged (except Bidesmida and possibly 2 other genera not in the area of this study). $M$ frequently narrowed between setae. In hind wing, $\mathrm{M}$ and $\mathrm{Cu}_{1}$ run close to each other for more than half the length of $\mathrm{Cu}_{1}$; frequently without any membrane showing between them. Rs branches off from $R$ near base of wing. Radio-medial cross-vein strikes stem of Rs basally of radial cross-vein and strikes $M$ (when $M$ is forked) on the anterior branch.

Plicaturae present on sterna 3-6. Wax glands of abdomen in a narrow transverse band on each of first eight terga (except one genus not in area of present study) and surrounding plicaturae. Eighth segment normally with stigmata. Ninth segment of males strongly sclerotized. 
Larvae with antennae and labial palpi of about equal length. Jaws long, slender, projecting from beneath labrum for more than half their length.

Notes: There are 4 known genera of this subfamily within the area of this study.

Key to North American genera of Aleuropteryginae

1. Radial cross-vein in hind wing strikes $R s$ on branch $R_{2+3} \ldots$

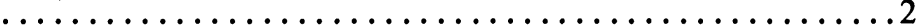

Radial cross-vein in hind wing strikes Rs on stem or on fork

2. Seventh sternum of male with plicaturae.............3

Seventh sternum of male without plicaturae..... Helicoconis

3. Bases of medial setae distinctly thickened.......... Neoconis Bases of medial setae not distinctly thickened.

Medial setae not prominent ................. Bidesmida

Genus Aleuropteryx Low, 1885

Aleuropteryx Low, 1885:79. Type, by monotypy, Aleuropteryx Lowii Klapalek, 1894.

Antennae distinctly separated. Eyes small to medium. Head capsule and palpi usually dark.

Antennae 19-27 segmented. Scape and pedicel elongate; male pedicel with distinct ventral spine. Flagellar segments varying in length, usually as long as or longer than broad; hairs not arranged in distinct whorls.

Palpi unicolorous and slender, last segments of both labial and maxillary palpi only slightly broader than preceding segments. Basal segments of labial palpi distinctly longer than broad.

Fore wings (Fig. 1) short, subtriangular, usually slightly more than twice as long as broad. Usually 2 basal cross-veins in costal area. Sc forks distally of radial cross-vein, which usually strikes $\mathbf{R}_{2+3}$, but sometimes strikes fork or stem of Rs. $\mathbf{R}_{4+5}$ coalesces with $\mathbf{M}_{1+2}$ in most specimens, but may be connected by a cross-vein which superficially appears to be a branch of $\mathrm{M}$. $\mathrm{M}$ not thickened at bases of setae. Cross-veins rs-m and $m-c_{1}$ strike $M$ close to each other in middle of wing. $\mathrm{Cu}_{2}$ sinuous, parallel with hind margin in all North American species. Sc, $R_{1}$, distal end of $R_{2+3}$ and basal parts of $\mathrm{Cu}_{1}$, $A_{1}$ and $A_{2}$ thicker than other veins and bearing hairs. Longitudinal 


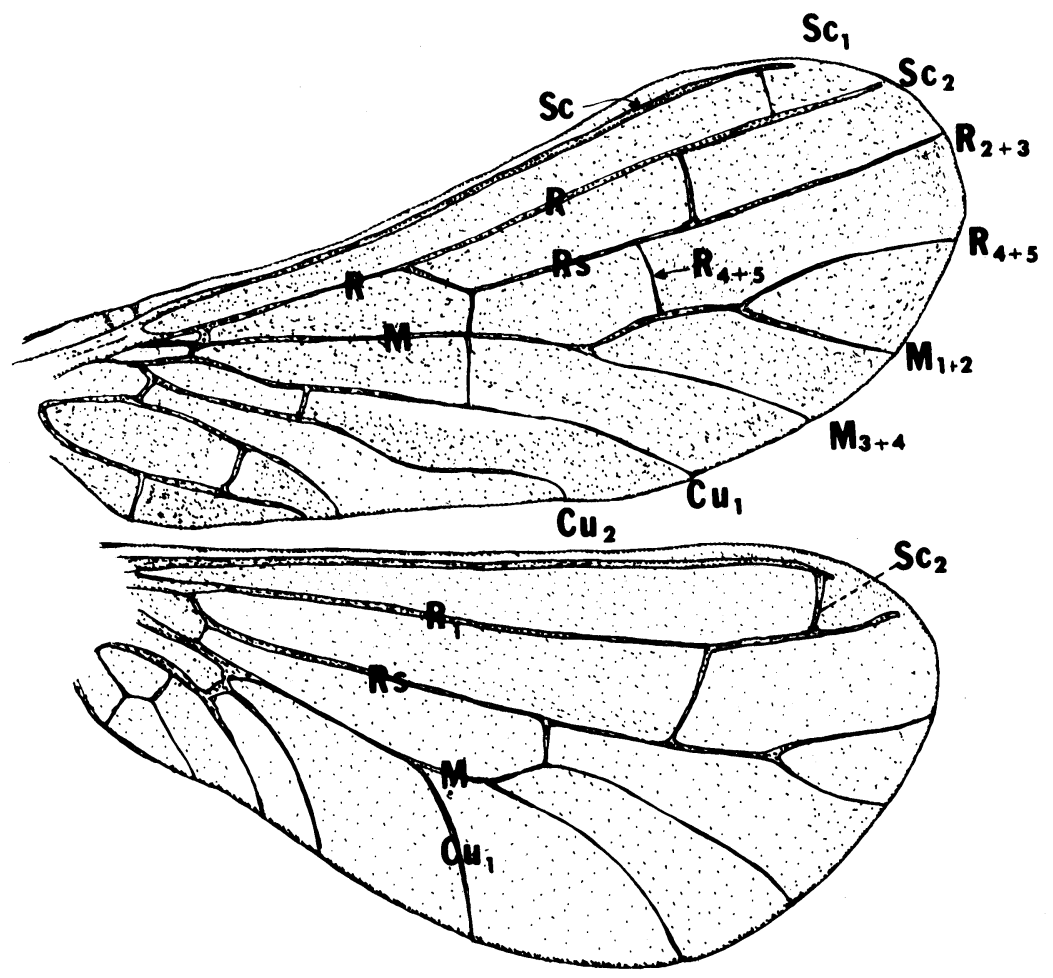

Figure 1. Wings of Aleuropteryx werneri

veins usually dark and cross-veins light, except $\mathrm{cu}_{1}-\mathrm{cu}_{2}$ and posterior part of cross-vein $\mathrm{m}-\mathrm{cu}_{1}$, which are dark. Marginal fringes short.

Hind wings usually slightly more than twice as long as broad. Usually 2 basal cross-veins in costal area. Sc forking distally of radial cross-vein, which strikes stem of Rs. Sc and distal parts of $R_{1}$ and $R_{2+3}$ thicker than other veins and having hairs. Marginal fringe short.

Abdomen weakly sclerotized with limits of terga and sterna somewhat indistinct. Distinct plicaturae on segments 3-6 in both sexes and occasionally discernible on segment 2 . Single narrow dorsal band of wax glands on segments 2-8 and surrounding plicaturae.

Male genitalia strongly sclerotized and basically internal. Ninth tergum obliterate. Ninth sternum modified, dorsally fused in all 
North American species to form a ring through which the penis protrudes. Ventrally and anteriorly, 9th sternum has lateral apophyses (except in 2 species not within the area of this study). Ventrally and posteriorly, 9th sternum has an unimpaired structure called the process of the 9 th sternum. Originating anteriorly of the process are paired structures called the appendages of the 9 th sternum. They are usually backwards and dorsally directed, bear hairs at their apical ends and are either fused distally or are connected to a transverse plate. Appendages of 9 th sternum are frequently membranous and difficult to delimit. Penis prominent with a pair of dorsolateral apodemes and a somewhat conical anterior one. Ectoprocts unsclerotized in all North American species, but sclerotized or otherwise modified in some other species.

Female genitalia with ectoprocts often indistinct. Gonapophyses laterales forming a sclerotized ventral plate. Bursa copulatrix sclerotized and differing interspecifically.

Notes: The male genitalia of Aleuropteryx differ from those of other genera and it is difficult to find homologous structures in other genera. The naming of structures in this case is for convenience and an attempt is made to standardize terminology. This has not always been the case in the past (Meinander 1972).

The shape of the bursa copulatrix and associated structures allow the females to be determined to species.

The larval stages of only one North American species ( $A$. juniperi) is known.

There are 14 species of this genus within the area of this study, 5 of which are herein described as new.

\section{Key to species - males}

1. Wings with distinct brownish spots $\ldots \ldots \ldots \ldots$ punctata Wings without distinct spots $\ldots \ldots \ldots \ldots \ldots \ldots \ldots \ldots . \ldots \ldots$

2. A pair of upward directed processes anterior to the process of

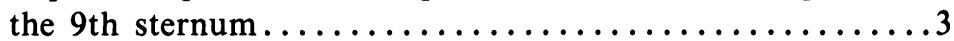
No such processes present $\ldots \ldots \ldots \ldots \ldots \ldots \ldots \ldots$...........

3. Processes anterior to process of 9 th sternum longitudinally flattened, plate-like and short $\ldots \ldots \ldots \ldots \ldots \ldots \ldots \ldots$ Processes anterior to process of 9th sternum spine-like and

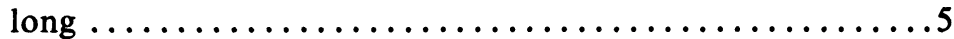


4. Process of 9th sternum ending in a central, caudally directed, pointed process .........................cupressi Process of 9 th sternum not as above........... werneri

5. Process of 9 th sternum with 4 caudally directed processes, 2 central and 2 lateral.................... dragoonica Process of 9th sternum ending in 3 processes, 1 central, 2 lateral .................... 6

6. Caudal projections of process of 9 th sternum subequal in

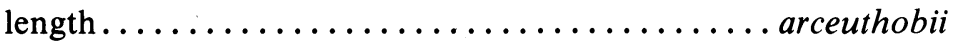
Central caudal projection of process of 9th sternum much larger than lateral ones ......................knowltoni

7. Sclerotized structure present just ventral to dorsal roof of 9th

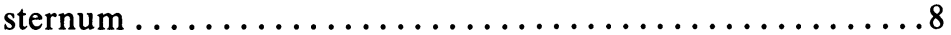

No such structure present $\ldots \ldots \ldots \ldots \ldots \ldots \ldots \ldots$

8. Structure just ventral to dorsal roof of 9 th sternum with 4 caudal projections....................... simillima Structure with 2 caudal projections ............... 9

9. Two caudal projections strongly curved forward at the tip to form pronounced hook ............... maculipennis Two caudal projections only slightly bent ventrally at tip .. arizonica

10. Penis ending posteriorly in 3 small, subequal projections... ................................. juniperi Penis not as above..........................11

11. Process of 9 th sternum simple.............. vulgaris Process of 9th sternum with an incision; not simple ....12

12. Penis ending posteriorly in 2 lateral processes..... unicolor Penis ending posteriorly in a ventral and a dorsal process... ......................................

13. Dorsal process of penis as long as or longer than ventral process.......................... longipennis Ventral process of penis much longer than dorsal process .. megacornis

Aleuropteryx arceuthobii Meinander, 1975

Aleuropteryx arceuthobii Meinander, 1975 p. 28. Type: Holotype male; Colorado; USNM.

Head: Dark brown. Antennae 20-25 segmented; brown. Scape and pedicel about twice as long as broad; proximal flagellar 
segments about as long as broad; median and distal flagellar segments almost twice as long as broad. Ventral spine on male pedicel about one fourth the length of the segment from the distal end.

Thorax: Brown with dark brown shoulder spots.

Wings: In fore wing $\mathrm{R}_{4+5}$ coalesces for a considerable distance with $\mathrm{M}_{1+2}$. $\mathrm{Cu}_{2}$ only slightly sinuous. Membrane of wing grey-brown with light areas around radial cross-vein and about the m-cu crossvein. Membrane of hind wing light greyish. Length of fore wing 2.2-2.4 mm, hind wing 1.9-2.2 $\mathrm{mm}$.

Male genitalia (Fig. 2): Ring of 9th sternum dorsally forming a

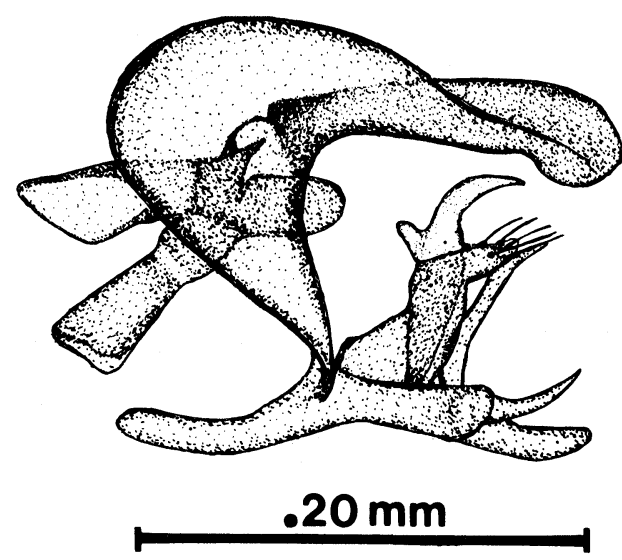

Figure 2. Aleuropteryx arceuthobii. Male genitalia, lateral view.

folded horizontal plate. Process of 9th sternum with three caudal processes, 1 central and 2 lateral. Lateral processes slightly dorsad to central one and curving slightly dorsad. A pair of slender, dorsally directed spines arises cephally of process of 9 th sternum and ending caudally of transverse plate. Appendages of 9 th sternum connected distally to transverse plate and bearing 4 long setae on a pair of caudally directed processes postero-lateral to the transverse plate. Transverse plate with 2 curved processes directed dorsally, a laterally flattened ventral process and 2 short acute anteriorly directed processes. Apophyses of 9th sternum long and slender. Penis ending caudally in 2 lateral plate-like processes and a central cone-shaped process containing a duct. 
Female and immature stages unknown.

Previous distribution: Colorado.

New material examined: TEXAS*: El Paso. VI-27-28-1976, 2 males, C. L. Sperka, blacklight trap: VI-3-4-1976, 1 male, C. L. Sperka, blacklight trap.

Notes: The present specimens from Texas differ slightly from the holotype. The lateral processes on the 9 th sternum are closer to the central process on the holotype than on the Texas specimens. The 3 Texas specimens have 20 antennal segments and the holotype has 25. The wing length of the holotype is within the range of the wing lengths of the Texas specimens. The length of the coalescence of $\mathbf{R}_{4+5}$ and $\mathbf{M}_{1+2}$ is long in all specimens but varies considerably. In 1 specimen, the coalescence begins near the radio-medial cross-vein in 1 wing and about halfway between the radio-medial cross-vein and the fork of $M$ in the other wing.

Meinander considered the paired processes caudo-lateral to the transverse plate to be part of the transverse plate. I prefer to consider them to be part of the appendages of the 9th sternum. They bear setae, which is consistent with their being part of the appendages of the 9th sternum. Meinander also described the dorsal roof of the 9th sternum as having a deep caudal incision. The caudal part of the roof of the 9th sternum has a median area which is lightly sclerotized in comparison with lateral areas and this gives the appearance of a deep caudal incision.

\section{Aleuropteryx arizonica Johnson, new species}

Type: Holotype male; Arizona; INHS.

Head: Brown. Antennae 19-22 segmented; brown. Scape and pedicel twice as long as broad; first flagellar segment and distal flagellar segments about as long as broad; median flagellar segments slightly longer than broad. Ventral spine on male pedicel slightly basal to distal end.

Thorax: Brown with blackish brown shoulder spots.

Wings: In fore-wing $R_{4+5}$ coalesces with $\mathbf{M}_{1+2}$ for a distance varying with specimen from long to short. $\mathrm{Cu}_{2}$ distinctly sinuous. Membrane of fore-wing greyish with darker shades along margin between veins. Hind-wing lighter without darker shading. Length of fore-wing $1.9-3.4 \mathrm{~mm}$, hind-wing $1.7-3.0 \mathrm{~mm}$. 
Male genitalia (Fig. 3A-C): Ring of 9th sternum dorsally forming a horizontal plate. Process of 9th sternum large in lateral view with a downward directed flap, shield-shaped in caudal view. Appendages of 9th sternum lightly sclerotized, connected with transverse plate and bearing setae caudo-lateral to transverse plate. Transverse plate formed of $2 \mathrm{C}$-shaped structures, free dorsally and fused ventrally into a short ventrally directed process. Free ends flattened dorso-ventrally, truncate in dorsal view, somewhat pointed in lateral view. Penis ending posteriorly in 2 ventro-lateral processes and a central, cone-shaped process containing a duct. A pair of processes just ventral to dorsal roof of 9th sternum. Caudal ends slightly curved ventro-laterally. Anterior portions much flattened dorso-ventrally and very wide, joining together to form a slightly folded membranous sheath attached to penis and to lateral portion of ring of 9th sternum. Ectoprocts weakly sclerotized.

Female genitalia (Fig. 3D-E): A well-sclerotized subgenital plate present. Bursa copulatrix a strongly sclerotized tube. Dorso-caudally, a sclerotized structure, dentiform in lateral view and truncate in ventral view.

Immature stages unknown.

Holotype male: ARIzona: Pinal Co., near Superior, Boyce

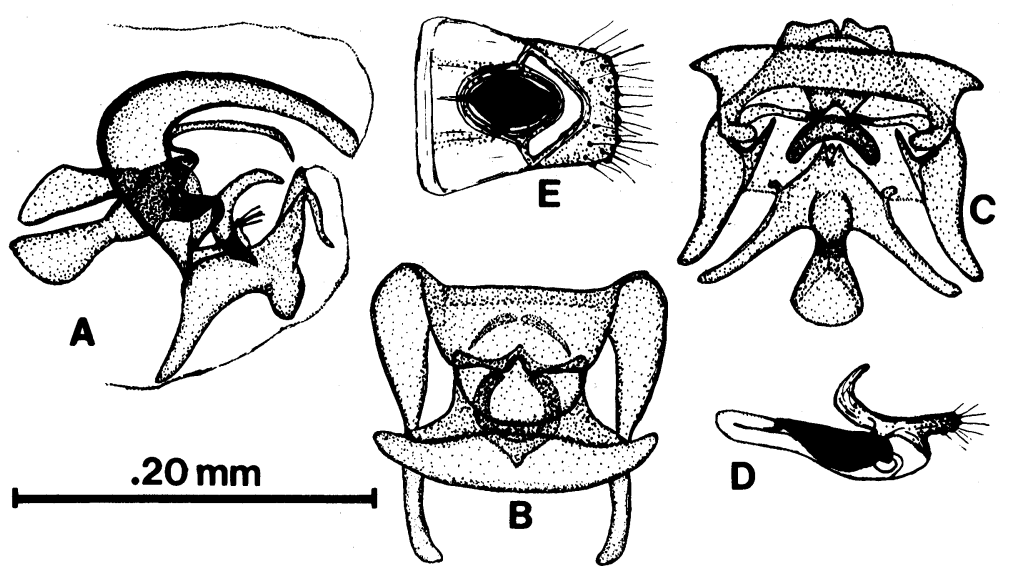

Figure 3. Aleuropteryx arizonica. A. Male genitalia, lateral view. B. Male genitalia, caudal view. C. Male genitalia, ventral view. D. female genitalia, laterial view. E. Female genitalia, ventral view. 
Thompson Southwestern Arboretum, VII-11-1949, B. W. Benson, light trap.

Paratypes: ARIzona: Superior, Pinal Co., V-2-8-1946, 1 male, B. W. Benson, at light; VII-16-VIII-5-1948, 9 males 7 females, H. K. Gloyd, at light; Pinal Co., near Superior, Boyce Thompson Southwestern Arboretum, IV-26-1949, 1 female, B. W. Benson; VII-111949, 5 males, B. W. Benson; Sabino Co., Catalina Mt., IV-4-1958, 1 male, M. Adachi; Chutum Vaya Cn., Baboquivari Mts., 3250', VIII-4-1966, 1 male 1 female, F. Werner family. Deposited: INHS, USNM, ARIZ; AUTH.

Aleuropteryx cupressi Meinander, 1974

Aleuropteryx cupressi Meinander, 1974:218. Type: Holotype male; California; UCA.

Head: Dark brown. Color of eyes of both sexes light brown. All segments of antennae of both sexes about twice as long as broad. Ventral spine of male pedicel situated slightly distad of middle of segment.

Thorax: Dark brown.

$\mathbf{R}_{4+5}$ and $\mathbf{M}_{1+2}$ of fore wing coalesces for a short distance. $\mathbf{C u}_{2}$ distinctly sinuous. Membrane of both wings unicolorous yellowish brown. Length of fore wing 3.2-3.6 mm, of hind wing $2.8-3.2 \mathrm{~mm}$.

Male genitalia (Fig. 4A): Ring of 9th sternum rather broad, dorsally longitudinally folded and apically with a rather deep incision. Apophyses of 9th sternum long and slender. Process of 9th sternum posteriorly with a caudally directed tapering process and apically dorsally a pair of flattened upwards and backwards directed processes. Appendages of 9th sternum membranous and apically connected to transverse plate. Transverse plate in lateral view hook-
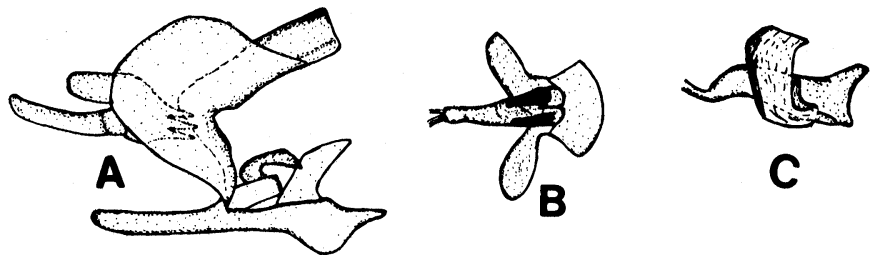

Figure 4. Aleuropteryx cupressi. A. Male genitalia, lateral view. B. Female genitalia, ventral view. C. Female genitalia, lateral view (Redrawn from Meinander 1974) 
like and apically backward directed and bifurcate. Penis ending apically in 1 dorsal, 2 lateral and 1 ventral spine. Ectoprocts weakly sclerotized.

Female genitalia (Fig. 4B-C): A well-sclerotized subgenital plate present. Bursa copulatrix a strongly sclerotized tube with a pair of large transverse dorso-lateral apodemes. Apically dorsally a well sclerotized structure, which in lateral view is dentiform.

Immature stages unknown.

Distribution: California.

New material examined: None.

Notes: Description from Meinander (1974). I agree with Meinander that the apical ends of the appendages of the 9th sternum are attached to the transverse plate. It is likely that the appendages of the 9th sternum possess setae apically, although Meinander does not mention them in his description. All related species have such setae.

\section{Aleuropteryx dragoonica Johnson, new species}

Type: Holotype male; Arizona; USNM.

Head: Brown, slightly reddish in some specimens. Antennae 20-22 segmented; brown. Scape and pedicel about twice as long as broad, proximal flagellar segments about as long as broad, median and distal flagellar segments 1.5 times as long as broad. Ventral spine on male pedicel sub-terminal.

Thorax: Brown with dark brown shoulder spots.

Wings: In fore wing, $\mathbf{R}_{4+5}$ coalesces for a considerable distance with $\mathbf{M}_{1+2} ; \mathrm{Cu}_{2}$ distinctly sinuous, brownish with lighter areas near veins. Hind wing with membrane lighter, greyish. Length of fore wing 2.4-2.8 $\mathrm{mm}$, hind wing $2.1-2.4 \mathrm{~mm}$.

Male genitalia (Fig. 5A-C): Ring of 9th sternum dorsally forms a folded horizontal plate. Process of 9th sternum with 4 caudally directed processes: the 2 lateral ones originate on the dorsal surface, bend medially at about the midpoint in their length and curve dorsally; 2 median processes, 1 dorsal and 1 ventral. A pair of slender spines originate cephally of process of 9th sternum and end caudally of transverse plate. Spines project antero-dorsally for most of their length and then bend caudo-dorsally. Appendages of 9th sternum connected distally to transverse plate and bearing 4 setae caudo-laterally to transverse plate. Transverse plate with 2 curved processes free dorsally and joined ventrally to form a laterally 
flattened downward directed process. Two short, acute, anterolateral processes near point where processes join. Apophysis of 9th sternum short. Penis caudally with 2 ventro-lateral processes and a central, cone-shaped process bearing duct. Ectoprocts weakly sclerotized.

Female genitalia (Fig. 5D-E): Gonapophyses laterales strongly sclerotized to form an unpaired ventral plate. Bursa copulatrix strongly sclerotized, long.

Immature stages unknown.

Holotype male: ARIzona: Cochise Stronghold, Dragoon Mts., VIII-15-18-1969, R. J. Shaw, light trap.

Paratypes: ARIzona: Cochise Stronghold, Dragoon Mts., VIII18-21-1969, 1 female, R. J. Shaw, light trap; IV-17-21-1970, 1 male, R. J. Shaw, light trap; VI-10-15-1970, 2 females, R. J. Shaw, light trap; VI-15-20-1970, 1 female, R. J. Shaw, light trap; VII-24-27-
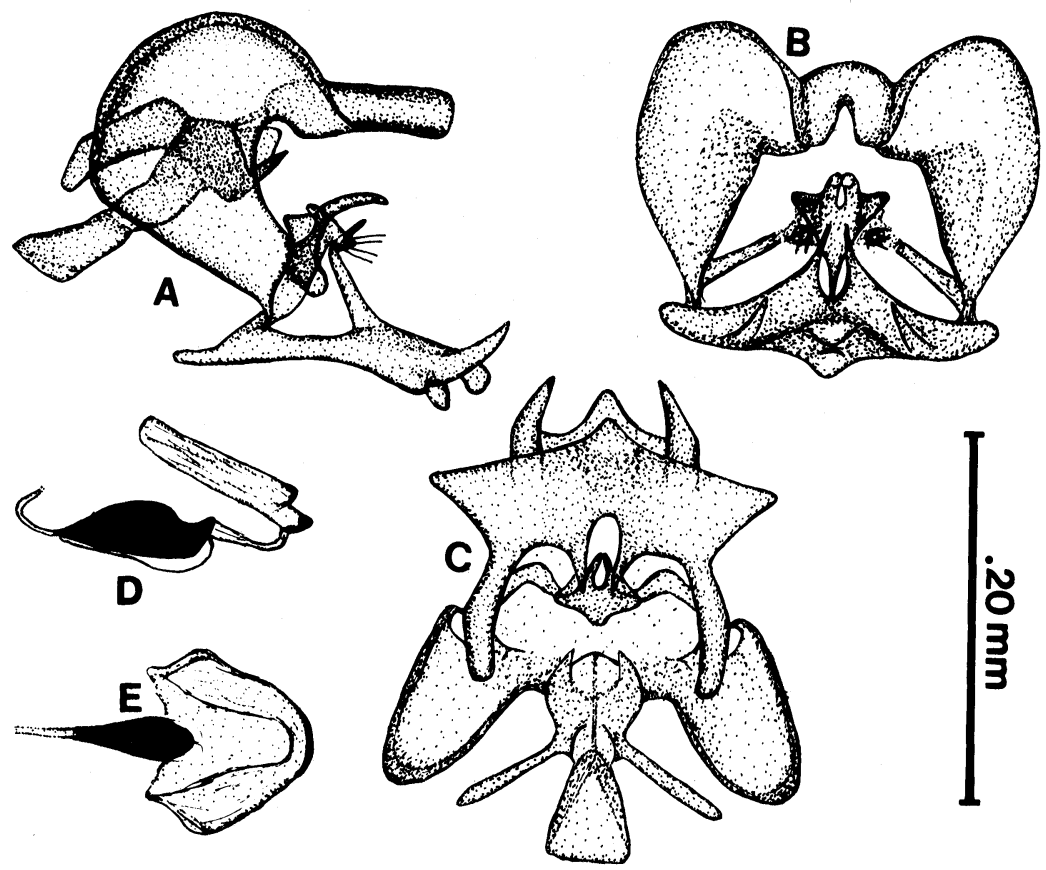

Figure 5. Aleuropteryx dragoonica. A. Male genitalia, lateral view. B. Male genitalia, caudal view. C. Male genitalia, ventral view. D. Female genitalia, lateral view. E. Female genitalia, ventral view. 
1970, 1 male, R. J. Shaw, light trap; VIII-6-9-1970, 1 female, R. J. Shaw, light trap; VIII-12-16-1970, 1 female, R. J. Shaw, light trap; IX-9-14-1970, 1 female, R. J. Shaw, light trap; IX-21-28-1970, 1 female, R. J. Shaw, light trap. Deposited: USNM, ARIZ; AUTH.

Notes: The females described above are associated with the males of $A$. dragoonica by similarities in size, coloration, antennal and wing characteristics and by similarities in distribution. Under the circumstances, it is not possible to state definitely that the above mentioned females are conspecific with $A$. dragoonica but they are assumed to be until shown otherwise.

This species is named after the type locality, Dragoon Mountains.

\section{Aleuropteryx juniperi Ohm, 1968}

Aleuropteryx juniperi Ohm, 1968:14. Type: Holotype male: Germany: Coll. Ohm.

Head: Brown. Antennae 22-23 segmented, almost unicolorous greyish brown. Scape about twice as long as broad, pedicel about two-thirds the length of the scape. Ventral spine of male pedicel close to distal end of pedicel. Flagellar segments distinctly longer than broad.

Thorax: Brown with blackish brown shoulder spots.

In fore wing, $\mathbf{R}_{4+5}$ and $\mathbf{M}_{1+2}$ vary from short coalescence to connection by a cross-vein. $\mathrm{Cu}_{2}$ distinctly sinuous. Membrane of fore wing greyish brown with irregular areas of dark shading, especially near margin. Length of fore wing $2.5-2.8 \mathrm{~mm}$, hind wing 2.2-2.5 mm.

Male genitalia (Fig. 6A): Ninth sternum rather narrow, dorsally with 3 lateral, caudally directed processes which are folded longitudinally. Process of 9 th sternum simple. Appendages laterally
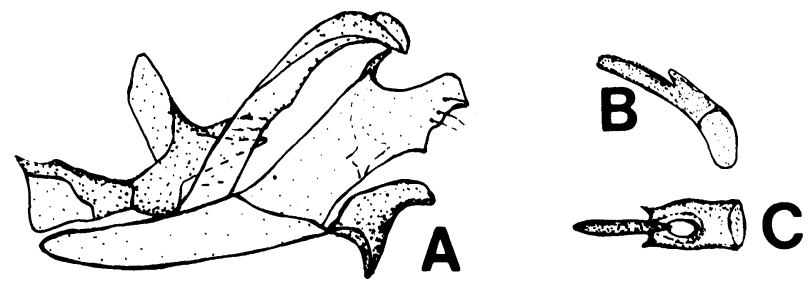

Figure 6. Aleuropteryx juniperi. A. Male genitalia, lateral view. B. Female genitalia, lateral view. C. Female genitalia, ventral view. (Redrawn from Meinander, 1972) 
flattened, large, connected by transverse plate. Appendages with small group of setae distally. Transverse plate formed of a pair of curved, dorsally directed processes which are ventrally connected. A pair of small ventral projections of transverse plate present. Penis ending posteriorly in 3 processes, 2 ventro-lateral and one central.

Female genitalia (Fig. 6B-C): Gonapophyses laterales sclerotized, forming an unpaired genital plate. Bursa copulatrix with a strongly sclerotized anteriorly narrowed part and a posterior, less strongly sclerotized part.

Immature stages described by Ward (1970).

Previous distribution: Western and Central Europe and United States.

New material examined: None.

Notes: This species was recently reported from the United States for the first time (Henry 1974, 1976 and Flint 1974). It has apparently become well established and is extending its distribution westward in the U.S. (Flint, personal communication).

This species feeds on scale insect pests of conifers, mainly Juniperus sp.

\section{Aleuropteryx knowltoni Johnson, new species}

Type: Holotype male; Utah; USNM.

Antenna 23-25 segmented. Scape, pedicel and flagellar segments twice as long as broad. Ventral spine on male pedicel about onefourth the length of segment from distal end.

Thorax: Brown with dark shoulder spots.

Wings: In fore wing $R_{4+5}$ coalesces for a considerable distance with $\mathrm{M}_{1+2}$. $\mathrm{Cu}_{2}$ distinctly sinuous. Membrane of wings unicolorous with fore wing darker than hind wing. Length of fore wing 3.4-4.0 $\mathrm{mm}$, hind wing $2.6-3.8 \mathrm{~mm}$.

Male genitalia (Fig. 7A-C): Ring of 9th sternum dorsally forming a folded horizontal plate, caudally with lateral areas heavily sclerotized and central area only lightly sclerotized. process of 9th sternum with 3 processes, a backward directed and dorsally curving central process and 2 small slightly curved processes extending dorso-caudally. The small processes located dorso-laterally to central process. A pair of slender dorsally directed spine-like processes originating cephally of process of 9th sternum and ending caudally of transverse plate. Appendages of 9 th sternum connected distally with transverse plate and having a pair of knob-like processes 


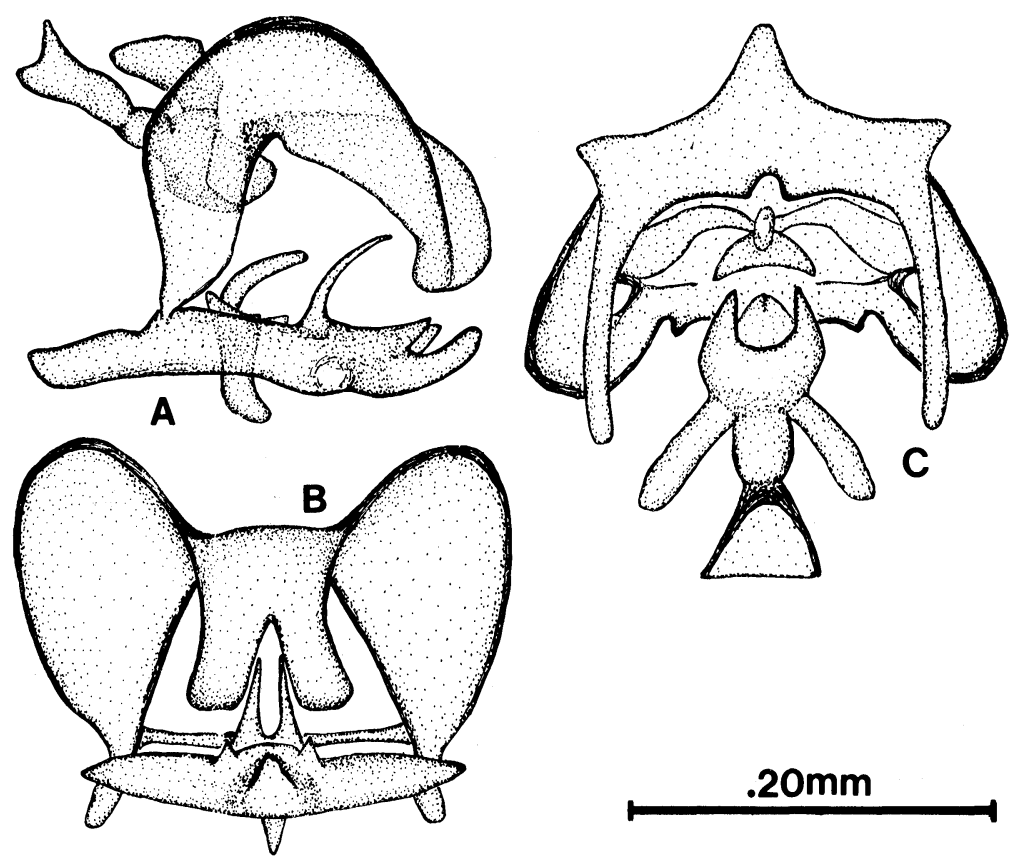

Figure 7. Aleuropteryx knowltoni. A. Male genitalia, lateral view. B. Male genitalia, caudal view. C. Male genitalia, ventral view

caudo-lateral to transverse plate bearing 4 setae. Transverse plate formed of 2 curved dorsally directed processes joined ventrally to form a large laterally flattened ventral process and a pair of small, acute antero-lateral processes. Apophyses of 9th sternum short, laterally flattened. Penis ending posteriorly in 2 large, laterally flattened, lateral processes and a central cone-shaped process with duct.

Female and immature stages unknown.

Holotype male: UTAH: Logan, VI-29-1950, G. F. Knowlton.

Paratypes: UTAH: Logan, VI-29-1938, 1 male, G. F. Knowlton and D. E. Hardy, at light; VI-19-1950, 1 male, G. F. Knowlton; College, VI-29-1938, 1 male, L. Cutler. Deposited: UTAH; AUTH.

Notes: All specimens have been preserved in ethyl alcohol for a long time and have lost most of their color. Therefore, I have omitted references to color in the description.

This species is dedicated to G. F. Knowlton. 
Aleuropteryx longipennis Meinander, 1974

Aleuropteryx longipennis Meinander 1974, p. 218. Type: Holotype male; Baja California; UCA.

Head: Dark brown to black. Antennae 24-26 segmented, dark brown to black. Scape and pedicel about twice as long as broad; first flagellar segment about as long as broad; most of remaining flagellar segments about twice as long as broad. Ventral spine of male pedicel about one-fourth the length of segment from distal end.

Thorax and legs: Dark brown to black.

Wings: $\mathbf{R}_{4+5}$ and $\mathrm{M}_{1+2}$ coalesces for short distance. $\mathrm{Cu}_{2}$ sinuous. Membrane of wings unicolorous light grey-brown. Length of wings vary greatly: fore wing $2.5-4.8 \mathrm{~mm}$, hind wing $2.1-4.1 \mathrm{~mm}$.

Male genitalia (Fig. 8): Ring of 9th sternum dorsally forming a folded horizontal plate, apically curved ventrally then anteriorly for short distance. Small incision in caudal view. Process of 9 th sternum with a horizontal backward directed flap with lateral areas thicker than central area, forming a dorsal incision in caudal view and with a rounded incision in ventral view, one-third the length of flap. Appendages of 9 th sternum partly membranous, connected apically with transverse plate and bearing 4 short setae apically. Transverse plate rather small, formed by 2 curved processes joined ventrally and free dorsally. Two small acute antero-lateral processes slightly dorsal to point where curved processes join. Apophyses of 9th sternum very long and slender. Penis ending posteriorly in 2 processes: a ventral dorsally curving, spine-like process and a more

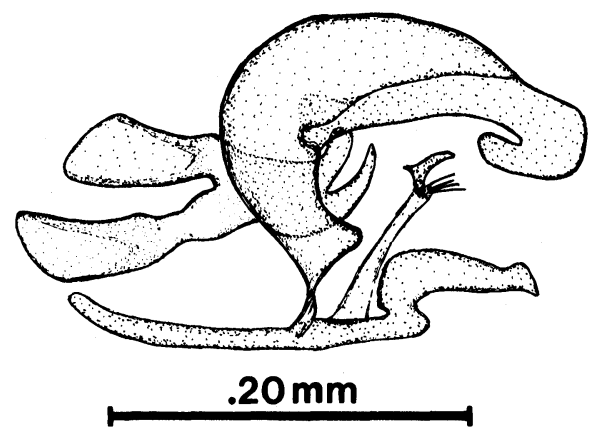

Figure 8. Aleuropteryx longipennis. Male genitalia, lateral view. 
anterior, cylindrical, dorsally directed process with duct. Ectoprocts weakly sclerotized.

Female and immature stages unknown.

Previous distribution: California and New Mexico; Mexico: Baja California.

New material examined: UTAH*: Logan, VI-2-1938, 1 male, G. F. Knowlton, D. E. Hardy and G. S. Stains, at light.

Notes: Meinander referred to the transverse plate as being between the apices of the apophyses of the 9th sternum in his description. He was apparently referring to the apices of the appendages of the 9th sternum.

The present specimen is the 4th known specimen of this species.

Aleuropteryx maculipennis Meinander, 1972

Aleuropteryx maculipennis Meinander, 1972, p. 45. Type: Holotype male; California; CAS.

Head: Dark brown. Antennae 20-23 segmented, dark brown. Scape and pedicel about twice as long as broad; first flagellar segment about as long as broad to twice as long as broad; proximal flagellar segments 1.5 times as long as broad; median flagellar segments one 1.5-2.0 times as long as broad; distal flagellar segments slightly longer than broad to 1.5 times as long as broad. Ventral spine on male pedicel about one third the length of segment from distal end.

Thorax: Dark brown with blackish brown shoulder spots. Legs dark brown with tarsi lighter.

Wings: In fore wing $R_{4+5}$ coalesces with $M_{1+2}$ for a short to moderate distance. $\mathrm{Cu}_{2}$ distinctly sinuate. Membrane of fore wing greyish-brown with darker shades along margin between veins. Lighter areas around $\mathrm{r}-\mathrm{m}$ cross-vein and m-cu cross-vein. Some specimens with noticeable clear areas directly adjacent to veins. Hind wing lighter. Length of fore wing 2.2-3.8 mm, hind wing 1.9-3.4 mm.

Male genitalia (Fig. 9A): Ring of 9th sternum dorsally forming a folded horizontal plate. Process of 9th sternum large in lateral view with a downward directed, shield-shaped flap, narrower in caudal view than the flap of $A$. arizonica. Appendages of 9 th sternum connected distally to transverse plate and bearing setae just anterolateral to transverse plate. Transverse plate formed of 2 curved 

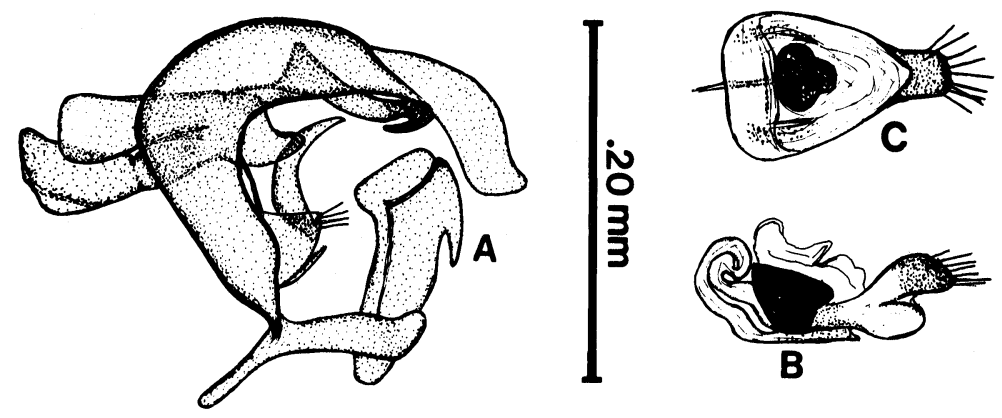

Figure 9. Aleuropteryx maculipennis. A. Male genitalia, lateral view. B. Female genitalia, lateral view. C. Female genitalia, ventral view.

processes joined ventrally to form a short ventral process. Free ends of processes directly dorsally, slightly dorso-ventrally flattened, pointed in lateral view and truncate in dorsal view. A pair of well sclerotized structures ventral to dorsal roof of ring of 9th sternum. Caudal ends of processes strongly sclerotized and bent forward ventrally to form hook-like structures. Anterior ends of structures broadened in lateral view and truncate. The ventral parts of these anterior ends broadened laterally and fused together to form a broad, somewhat membranous structure attached to dorsal and lateral sides of penis and also probably to ring of 9th sternum anteriorly and laterally. Penis ending posteriorly in 3 processes, 2 ventro-lateral spine-like processes slightly laterally flattened and a central cone-like process.

Female genitalia (Fig. 9B-C): Gonapophyses laterales sclerotized and fused to form an unpaired median plate. Strongly sclerotized part of bursa copulatrix somewhat heart-shaped in lateral view and tri-lobed in ventral view. A complicated folded ventral apodeme present and a caudal dentiform structure which is strongly sclerotized and easily visible externally.

Immature stages unknown.

Previous distribution: U.S.A.: California.

New material examined: U.S.A.: ARIZONA*: Superior, Pinal Co., VII-16-VIII-5-1948, 5 males 10 females, H. K. Gloyd, at light; III19-1949, 1 female, B. W. Benson, at light; Pinal Co., near Superior, III-19-1949, 1 female, B. W. Benson, at light; Pinal Co., near Superior, Boyce Thompson Southwestern Arboretum, IV-26-1949, 1 male 1 female, B. W. Benson, light trap; VII-11-1949, 5 males, B. 
W. Benson, light trap; Pima Co., Sonora Desert Museum, VIII-5-81962, 2 males, W. L. Nutting and S. Oman, light trap; Ramsey Cn., Huachuca Mts., X-19-1966, 1 female, F. Werner, U.V. trap; Chutum Vaya Cn., Baboquivari Mts., VIII-4-1966, 1 male, F. Werner family, U.V. trap; Cochise Stronghold, Dragoon Mts., X-3-8-1969, 1 female, R. J. Shaw, light trap; V-12-17-1970, 1 female, R. J. Shaw, light trap; VI-5-10-1970, 1 female, R. J. Shaw, light trap; VI-10-151970, 1 female, R. J. Shaw, light trap; VI-15-20-1970, 1 female, R. J. Shaw, light trap; VI-2-24-1970, 2 females, R. J. Shaw, light trap; VI27-29-1970, 1 female, R. J. Shaw, light trap; VII-2-5-1970, 2 females, R. J. Shaw, light trap; VII-27-30-1970, 1 male, R. J. Shaw, light trap; VII-31-VIII-2-1970, 1 male, R. J. Shaw, light trap; VIII3-6-1970, 1 male, R. J. Shaw, light trap; VIII-6-9-1970, 1 male, R. J. Shaw, light trap; VIII-9-12-1970, 1 male 1 female, R. J. Shaw, light trap; VIII-12-16-1970, 1 female, R. J. Shaw, light trap; TEXAS*: El Paso, VI-3-4-1976, 1 male, C. L. Sperka, light trap.

Notes: Meinander described the transverse plate and the appendages of the 9th sternum as 1 structure and considered this to be the appendages of the 9th sternum. He considered the transverse plate to be absent. Occasionally, the transverse plate is pulled out of the normal position behind the posterior end of the penis to a more ventral position and in this location it is difficult to delimit. A transverse plate is present and the appendages of the 9th sternum are attached to it and are somewhat membranous and not tubular as described by Meinander. Meinander speculated that the hook-like structures just ventral to the dorsal roof of the 9th sternum might attach either to penis or to the ring of the 9th sternum. They are definitely attached to the penis and appear to be attached to the ring of the 9th sternum. Related species have similar structures attached both to the penis and to the 9th sternum. Previously, this species was known from 2 males.

The females described above are associated with the males of $A$. maculipennis by similarities in size, coloration, antennal and wing characteristics and by similarities in distribution. Under the circumstances, it is not possible to state definitely that the above mentioned females are conspecific with $A$. maculipennis but they are assumed to be until shown otherwise. 
Aleuropteryx megacornis Johnson, new species

Type: Holotype male; Arizona, USNM.

Head: Dark brown, almost black. Antennae 22E24 segmented, dark brown. Scape and pedicel twice as long as broad; first and second flagellar segments about as long as broad to slightly longer than broad; proximal flagellar segments 1.5 times as long as broad; median flagellar segments twice as long as broad; distal flagellar segments 1.5 times as long as broad. Ventral spine on male pedicel about one-fourth the length of the segment from distal end of pedicel.

Thorax: Dark brown with black shoulder spots.

Wings: In fore wing $\mathbf{R}_{4+5}$ and $\mathrm{M}_{1+2}$ coalesces for variable distance, $\mathrm{Cu}_{2}$ sinuate. Membrane of wing unicolorous grey-brown, veins dark and well defined, hind wing lighter. Length of fore wing 2.8-3.4 mm, hind wing $2.5-3.0 \mathrm{~mm}$.

Male genitalia (Fig. 10A-C): Ring of 9th sternum dorsally forms a folded horizontal plate with a small incision in caudal view. Process

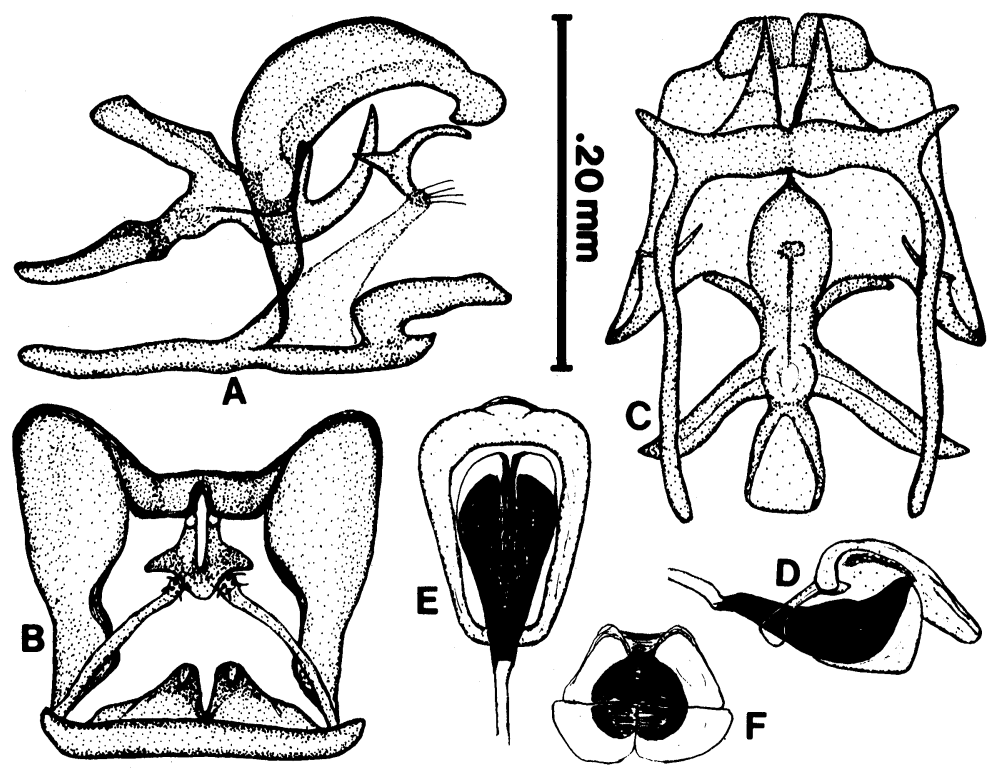

Figure 10. Aleuropteryx megacornis. A. Male genitalia, lateral view. B. Male genitalia, caudal view. C. Male genitalia, ventral view. D. Female genitalia, lateral view. E. Female genitalia, ventral view. F. Female genitalia, caudal view. 
of 9th sternum with a horizontal, caudally directed flap, deeply bisected to form 2 backward directed spines. Appendages of 9th sternum partially membranous, joined at distal ends with transverse plate and bearing setae caudo-lateral to transverse plate. Transverse plate formed of 2 dorsally directed, C-shaped processes, joined ventrally. Just dorsal to juncture, 2 acute antero-lateral processes. Apophyses of 9th sternum long and slender. Penis ending posteriorly in 2 processes. Postero-ventral 1 large, upward curved, widened anteriorly and narrowed posteriorly with sides extending dorsally on lateral edge in scoop-like shape. Antero-dorsal process of penis more or less cylindrical, arising dorsally within the hollow of the ventral process. Dorsal process bearing a duct.

Female genitalia (Fig. 10D-F): Gonopophyses laterales strongly sclerotized, forming a ventral unpaired plate. Strongly sclerotized part of bursa copulatrix large with a large postero-dorsal apodeme.

Immature stages unknown.

Male holotype: ARIzona: Cochise Stronghold, Dragoon Mts. V9-12-1970, R. J. Shaw, light trap.

Paratypes: ARIzona: Superior, Pinal Co., 1 female, VII-16-VIII5-1948, H. K. Gloyd, at light; Pinal Co., near Superior, Boyce Thompson Southwestern Arboretum, 1 female, IV-26-1949, B. W. Benson, light trap; Cochise Stronghold, Dragoon Mts., 1 male, V-912-1970, R. J. Shaw, light trap; Bowie, Cochise Co., 1 male 2 females, VII-28-1970, S. Kozloski, U.V. trap; Willcox, 1 female, VIII-9-10-1970, S. Kozloski, U.V. trap; NEW MEXICo: Las Cruces, 2 males 1 female, VI-30-1960, J. G. Watts; VIII-1-7-1975, 1 male, W. P. Morrison, light trap; TEXAs: El Paso, VII-15-16-1976, 1 female, C. L. Sperka, light trap. Deposited: USNM, INHS; AUTH.

Notes: A. megacornis is similar to A. longipennis but differs in the shape of the penis and the process of the 9th sternum. Megacornis has a much larger ventral spine on the posterior end of the penis than does longipennis and the horizontal flap on the process of the 9th sternum is deeply incised in megacornis but shallowly incised in longipennis.

The female specimens are associated with megacornis because of similarities in coloration, size, antennal and wing characteristics and distribution. It is possible that they represent a different species, but they will be considered as megacornis until shown otherwise. 
Aleuropteryx punctata Meinander, 1974

Aleuropteryx punctata Meinander, 1974:220. Type: Holotype male; Mexico; Sinaloa; UCR.

Head: Brown. Antennae 22E25 segmented. Scape dark brown, pedicel and proximal and medial part of flagellum light brown, then becoming darker distally. Scape and pedicel about twice as long as broad; proximal and distal flagellar segments slightly longer than broad; median flagellar segments 1.5 times as long as broad. Ventral spine on male pedicel about one-third the length of segment from distal end.

Thorax: Brown with blackish brown shoulder spots. Femora dark brown; tibiae lighter with dark proximal and distal ends; tarsi light brown.

Wing: In fore wing $\mathbf{R}_{4+5}$ and $\mathbf{M}_{1+2}$ coalesces for a considerable distance, $\mathrm{Cu}_{2}$ distinctly sinuate, in some specimens with a small vein between margin and $\mathrm{Cu}_{2}$ where it runs closest to the margin. Membrane of fore wing light with darker shades along margin between veins, scattered patches of light shading and discrete brown spots around cross-vein-like part of $\mathrm{Sc}_{2}$, base of Rs, radial crossvein, $r-m$ and $m-c u$ and around cross-vein-like part of $R_{4+5}$. Length of fore wing $2.4-3.0 \mathrm{~mm}$, hind wing $2.0-2.8 \mathrm{~mm}$.

Male genitalia (Fig. 11 A): Ring of 9th sternum dorsally forming a folded horizontal plate. Process of 9th sternum very large, high and broad in lateral view and narrow in caudal view with a downward directed caudal part. Appendages of 9 th sternum partly membranous, connected apically with transverse plate and bearing setae caudo-lateral to transverse plate. Transverse plate formed of $2 \mathrm{C}$ shaped processes, joined ventrally. Ring of 9 th sternum with a lateral pair of caudally directed, spine-like processes. A pair of processes just ventral to dorsal roof of ring of 9th sternum. Processes spine-like caudally; flattened and somewhat membranous anteriorly and covered with small denticles on the anterior half. Anterior end of processes attached to penis and probably to ring of 9 th sternum. Penis ending posteriorly in a flat, ventral process and a dorso-medial cone-like process. Apophyses of 9th sternum short.

Female genitalia (Figs. 11B-C): A well-sclerotized subgenital plate present. Bursa copulatrix a strongly sclerotized tube with 2 ventro-lateral apodemes. Bursa copulatrix surrounded by a large 

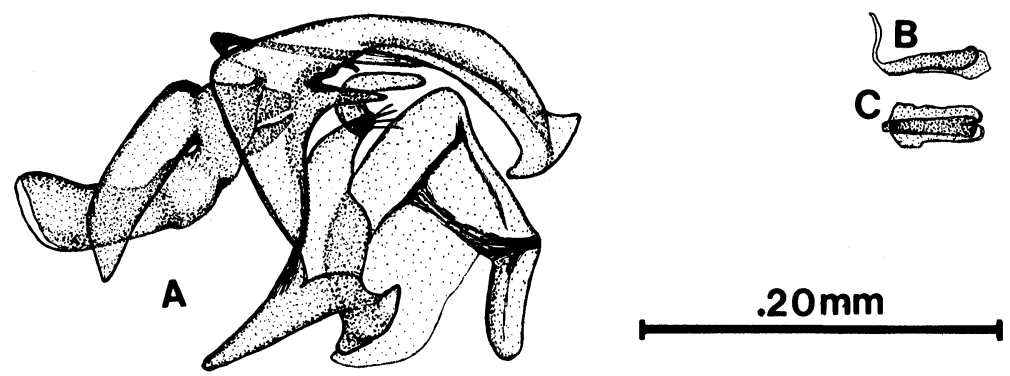

Figure 11. Aleuropteryx punctata. A. Male genitalia, lateral view. B. Female genitalia, lateral view. C. Female genitalia, ventral view.

unsclerotized folded tube, which ends in a small sclerotized knob with long setae.

Immature stages unknown.

Previous distribution: U.S.A.: Arizona; Mexico: Sinaloa.

New material examined: U.S.A.: NEW MEXICo*: Las Cruces, 1 male, VII-28-VIII-3-1975, W. P. Morrison, light trap; 1 male, V-3-61975, W. P. Morrison, light trap; MEXICo: Cholla Bay, 1 male, IV25-1959, M. S. Adachi.

Notes: Meinander referred to the appendages of the 9th sternum and the transverse plate as a forward directed process. This was evidently due to the transverse plate and appendages of the 9th sternum being pulled forward out of their normal position behind the process of the 9 th sternum. He erroneously considered the large process of the 9th sternum to be formed by the appendages of the 9 th sternum. The process of the 9 th sternum of $A$. punctata differs from the processes of maculipennis and arizonica mainly in size with that of maculipennis being larger.

Female genitalia, description and illustration from Meinander.

\section{Aleuropteryx simillima Meinander, 1972}

Aleuropteryx simillima Meinander, 1972:46. Type: Holotype male; Mexico (Baja California) CAS.

Head: Brown; eyes generally large. Antennae brown. Scape and pedicel about twice as long as broad; flagellar segments varying from slightly longer than broad to 1.5 times as long as broad. Ventral spine on male pedicel near distal end. 
Thorax: Brown with dark brown shoulder spots.

Fore wing: Brownish grey, with darker shade along margin between veins. Membrane lighter near veins. Some variation in color of wings with some specimens much lighter than others. In some specimens, darker shades along margin are very indistinct. Coalescence of $\mathbf{R}_{4+5}$ and $\mathbf{M}_{1+2}$ varies from long to short. $\mathrm{Cu}_{2}$ distinctly sinuous. Membrane of hind wing lighter than fore wing. Length of fore wing $1.8-3.8 \mathrm{~mm}$, hind wing $1.6-3.0 \mathrm{~mm}$.

Male genitalia (Fig. 12A-B): Ring of 9th sternum broad dorsally. Process of 9th sternum large and complex with a dorsal bifurcate part and a downward directed caudal part. Appendages of 9th sternum distally membranous and fused with transverse plate. Hairs present at apices. Transverse plate composed of 2 processes, fused ventrally and free dorsally. Dorsal part curved caudally. A sclerotized structure present just ventral to dorsal roof of 9 th sternum. This structure sheath-like anteriorly, connected to penis and apparently to ring of 9 th sternum; posteriorly ending in 4 flat, caudally directed spines. Except for the tip of the spines, entire structure covered with small denticles. Ring of 9th sternum with a pair of lateral, triangular projections, directed medially and caudally. Margin unevenly serrate. Penis ending posteriorly in a pair of ventro-
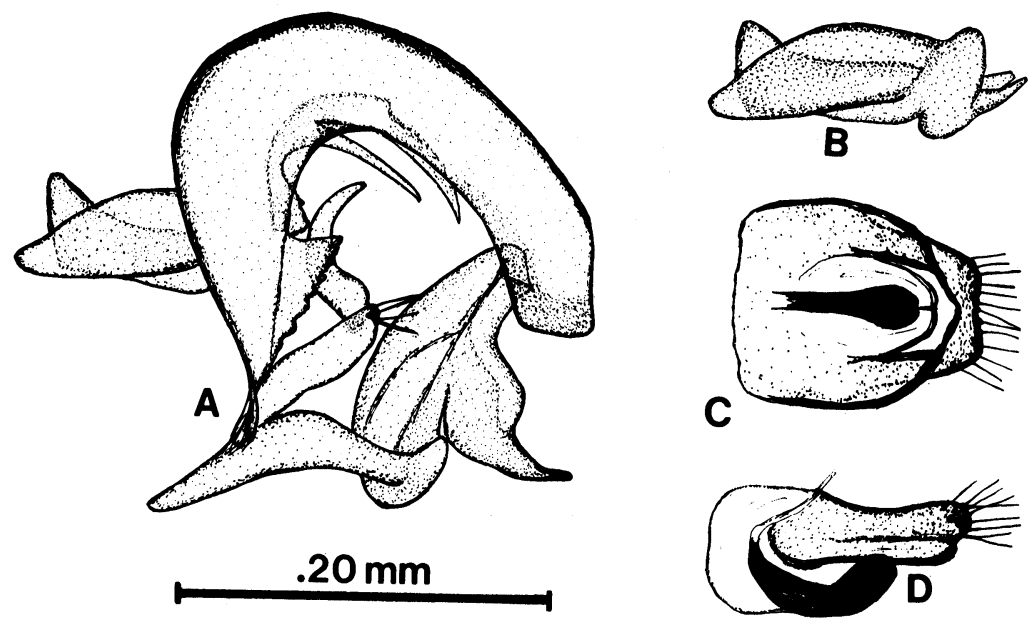

Figure 12. Aleuropteryx simillima. A. Male genitalia, lateral view. B. Penis, lateral view. C. Female genitalia, ventral view. D. Female genitalia, lateral view. 
lateral processes and a central comewhat cone-shaped process. Ectoprocts weakly sclerotized.

Female genitalia (Fig. 12C-D): Gonopophyses laterales fused to form ventral plate. Bursa copulatrix strongly sclerotized, anteriorly curved dorsally. Dorsally of bursa copulatrix, a sclerotized, horizontal structure. This plate-like structure is more strongly sclerotized along lateral and caudal margin and caudal margin bears several setae; ring-like in ventral or dorsal view.

Immature stages unknown.

Previous distribution: Northern Mexico and Texas.

New material examined: ARIzonA*: Superior, Pinal Co., 1 male, V-2-8-1946, B. W. Benson, at light; Pinal Co., near Superior, Thompson Arboretum \#1, 1 male, VI-7-1946, H. K. Gloyd, light trap; Superior, Pinal Co., 1 male, VII-16-VIII-5-1948, H. K. Gloyd, at light; 1 male, IV-1949, B. W. Benson, at light; near Superior, 1 female, IV-26-1949, B. W. Benson, light trap; near Superior, Boyce Thompson Southwestern Arboretum, 3 males 9 females, B. W. Benson, light trap; 1 male, X-3-1949, B. W. Benson, light trap; Chutum Vaya Canyon, Baboquivari Mt., 3250', 1 male 3 females, VIII-4-1966, F. Werner family, U.V. trap; $8 \mathrm{mi}$. N. Vail, 4 males, VIII-7-1966, F. Werner family, U.V. trap; Cochise Stronghold, Dragoon Mts., R. J. Shaw, black-light trap; 51 males 41 females from following dates: 1 female, VIII-12-15-1969; 1 female, IX-7-111969; 1 male 2 females, IX-11-15-1969; 1 male, X-3-8-1969; 4 males 1 female, V-9-12-1970; 1 female, V-12-17-1970; 1 male 2 females, V17-21-1970; 1 male, V-25-VI-2-1970; 1 male 1 female, VI-10-151970; 2 males 2 females, VI-15-20-1970; 1 male 4 females, VI-20-241970; 2 males 1 female, VI-29-VII-2-1970; 2 females, VII-2-5-1970; 1 male 1 female, VII-5-8-1970; 1 male 1 female, VII-8-10-1970; 1 male 3 females, VII-10-12-1970; 3 males 1 female, VII-12-15-1970; 2 males, VII-15-18-1970; 2 males, VII-18-21-1970; 1 male, VII-21-241970; 4 males 2 females, VII-24-27-1970; 2 males 1 female, VII-2730-1970; 1 male 1 female, VII-31-VIII-2-1970; 1 male 1 female, VIII3-6-1970; 2 males 4 females, VIII-6-9-1970; 2 males 3 females, VIII9-12-1970; 2 males, VIII-12-16-1970; 1 male 3 females, VIII-16-221970; 1 male, VIII-22-27-1970; 2 males 2 females, VIII-27-IX-11970; 1 male 1 female, IX-1-4-1970; 2 males, IX-4-9-1970; 1 male, IX-9-14-1970; 2 males 1 female, IX-14-21-1970; 3 males, IX-21-281970; Phoenix, 2 males 1 female, VII-13-1970, J. E. May, U.V. trap; Cochise Co., Bowie, 1 female, VII-29-1970, S. Kozloski, U.V. trap; 
Willcox, 1 male, VIII-9-10-1970, S. Kozloski, U.V. trap; NEW MEXICO*: Las Cruces, 1 male, X-9-1974, V. Johnson, blacklight trap; 1 male, IV-26-1975, V. Johnson, blacklight trap; 1 male, IV21-V-2-1975, W. P. Morrison, blacklight trap; 3 males 1 female, V13-23-1975, W. P. Morrison, blacklight trap; 2 males, VI-22-271975, W. P. Morrison, blacklight trap; 1 male, VII-28-VIII-1-1975, W. P. Morrison, blacklight trap; 1 male, VIII-1-7-1975, W. P. Morrison, blacklight trap.

Notes: This species was recently reported from Texas by Wheeler (1980). This was the first record from the U.S.

Aleuropteryx unicolor Meinander, 1972

Aleruopteryx unicolor Meinander, 1972:48. Type: Holotype male; California; UCA.

Head: Dark brown. Antennae dark brown, 21-23 segmented. Scape about 2.5 times as long as broad; pedicel twice as long as broad; proximal and distal flagellar segments about as long as broad; median flagellar segments 1.5 times as long as broad. Ventral spine on male pedicel almost at distal end.

Thorax: Dark brown with blackish brown shoulder spots.

Fore wing with $\mathbf{R}_{4+5}$ and $\mathbf{M}_{1+2}$ coalescing for a distance varying from short to long. $\mathrm{Cu}_{2}$ sinuous. Membrane of fore wing greyish brown, hind wing lighter. Length of fore wing $1.8-3.0 \mathrm{~mm}$, hind wing $1.6-2.7 \mathrm{~mm}$.

Male genitalia (Fig. 13A): Ring of 9th sternum dorsally forms a folded horizontal plate. process of 9th sternum large, with a dorsal pair of apophyses and a caudal apophysis. Appendages of 9th sternum distally membranous and connected to transverse plate. Appendages with setae at point of connection with transverse plate. Transverse plate represented by a pair of curved hooks, ventrally expanded and connected. Penis ending caudally in a large curved process. Ectoprocts weakly sclerotized.

Female genitalia (Fig. 13B-C): Subgenital plate well sclerotized. Heavily sclerotized portion of bursa compulatrix spherical in lateral view, somewhat wider in ventral view. Apically, a transverse horizontal plate, sclerotized along the apical margin and possessing 2 setae.

Previous distribution: California and Mexico (Baja California). New material examined: ARIzonA*: Superior, Pinal Co., 2 fe- 


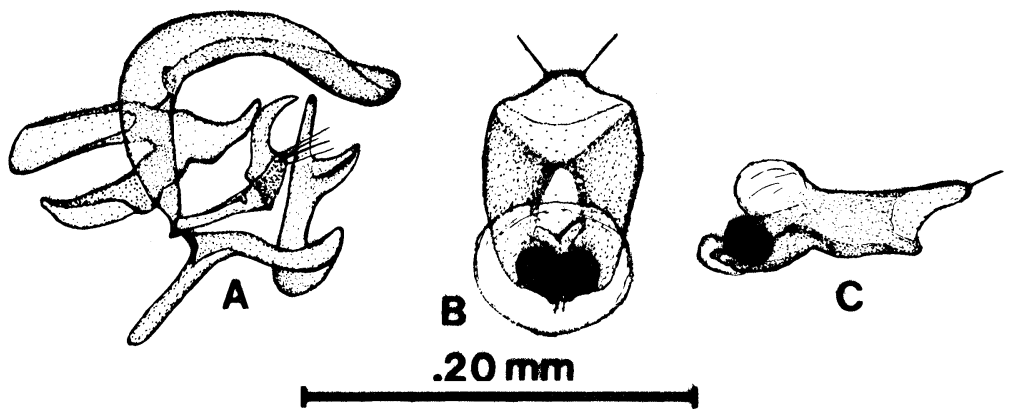

Figure 13. Aleuropteryx unicolor. A. Male genitalia, lateral view. B. Female genitalia, ventral view. C. Female genitalia, lateral view.

males, V-2-8-1946, B. W. Benson, at light; Cochise Stronghold, Dragon Mts., 1 male 1 female, V-17-21-1970, R. J. Shaw, blacklight trap.

Notes: Measurements above include those of Meinander and those of the new specimens from Arizona. The Arizona specimens account for the upper limits on wing measurements and the specimens of Meinander account for the lower limits. Meinander (1974) described the female genitalia from California specimens. At that time he illustrated and described 2 separate types of female genitalia. The type described as $A$. unicolor from Riverside, California, is identical to that of $A$. maculipennis newly described in the present work. The specimens he illustrated from Imperial Valley, California are what I consider to be $A$. unicolor. In addition, Meinander mentioned a 3rd type of genitalia from Mexico which probably represents another species.

\section{Aleuropteryx vulgaris Meinander, 1972}

Aleuropteryx vulgaris Meinander, 1972:51. Type: Holotype male;

Texas; USNM.

Head: Dark brown. Antennae 20-24 segmented. Scape and pedicel dark brown; flagellar segments varying from light greyish brown to dark brown. Scape and pedicel 1.5 times to twice as long as broad; flagellar segments of male varying from as long as broad to 2.5 times as long as broad; female flagellar segments about 1.5 times as long as broad. Ventral spine on male pedicel about onefourth the length of segment from distal end. Palpi brown. 
Thorax: Dark brown with blackish brown shoulder spots; legs brown.

Membrane of fore wing brown with lighter areas adjacent to veins, and between $R$ and $M$. In some specimens this is marked and gives the appearance of darker areas along margin between veins. In some specimens $\mathbf{R}_{4+5}$ coalesces for a long distance with $\mathbf{M}_{1+2}$ and in others they are connected by a cross-vein. $\mathrm{Cu}_{2}$ distinctly sinuous. Membrane of hind wing unicolorous, light greyish brown. Length of fore wing $1.7-4.1 \mathrm{~mm}$, hind wing $1.5-3.8 \mathrm{~mm}$.

Male genitalia (Fig. 14A): Ring of 9th sternum dorsally forming a folded horizontal plate. Process of 9th sternum simple, directed dorsally and caudally. Meinander (1972) reported the process ending in a small hook; the specimens at hand show only a very slight downward bend on the distal end. Appendages of 9th sternum distally membranous and attached to transverse plate. Setae present at distal ends. In some specimens a membranous structure can be seen extending from distal ends of appendages and apparently connected with ring of 9 th sternum. Transverse plate composed of 2 processes ventrally connected with dorsal ends free and curved caudally. Penis ending posteriorly in 2 ventral plate-like processes and a dorsal truncate process. Ventral processes curved slightly dorsally. Ectoprocts weakly sclerotized.
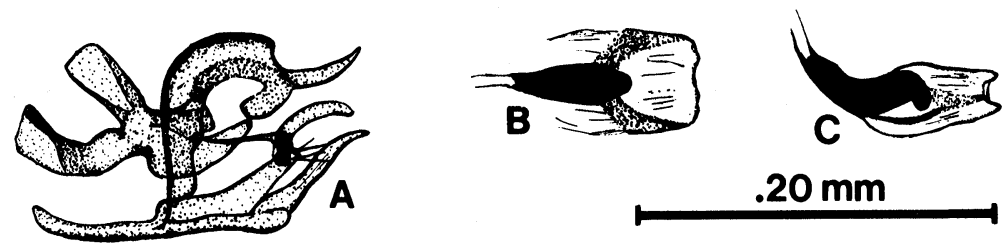

Figure 14. Aleuropteryx vulgaris. A. Male genitalia, lateral view. B. Female genitalia, ventral view. C. Female genitalia, lateral view.

Female genitalia (Fig. 14B-C): Conapophyses laterals sclerotized, forming unpaired ventral plate. Bursa copulatrix strongly sclerotized, at least in part, with a large, partially sclerotized apodeme. Heavily sclerotized portion of bursa copulatrix somewhat S-shaped in lateral view, with anterior part curved dorsally and posterior part bent ventrally.

Immature stages unknown. 
Previous distribution: Arizona, Calitornia, New Mexico, Texas and Utah.

New material examined: ARIZona: Pinal Co., Superior, 1 male 1 female, VII-16-VIII-5-1948, H. K. Gloyd, at light; Ramsey Canyon, Huachuca Mts., 1 male, VI-10-19-1966, F. Werner family, U.V. trap; Skull Valley, Yavapai Co., 1 male, VII-31-1970; Cochise Stronghold, Dragoon Mts., 47 males 67 females, R. J. Shaw, blacklight trap, following dates: 3 males 7 females, VIII-9-12-1969; 3 males, VIII-15-18-1969; 3 males 2 females, VIII-18-21-1969; 1 male, VIII-24-27-1969; 2 males 1 female, IX-3-7-1969; 1 male 2 females, IX-7-11-1969; 6 females, IX-11-15-1969; 1 female, V-21-26-1970; 2 males, V-25-V-12-1970; 1 male, VI-10-15-1970; 1 male 2 females, VI20-24-1970; 1 female, VI-27-29-1970; 1 male 2 females, VI-29-VII-21970; 2 males 1 female, VII-2-5-1970; 1 male 2 females, VII-10-121970; 1 female, VII-12-15-1970; 3 males 2 females, VII-15-18-1970; 2 males 2 females, VII-21-24-1970; 4 males 9 females, VII-24-27-1970; 1 male 12 females, VII-27-30-1970; 4 males, VII-27-29-1970; 1 male 5 females, VII-21-VIII-2-1970; 3 males 1 female, VIII-3-6-1970; 4 males 3 females, VIII-6-9-1970; 1 male 4 females, VIII-9-12-1970; 1 male 3 females, VIII-12-16-1970; 3 females, VIII-16-22-1970; 5 females, VIII-22-27-1970; 1 male 1 female, VIII-27-IX-1-1970; 2 males 2 females, IX-1-4-1970; 1 female, IX-4-9-1970; 1 female, IX14-21-1970; Coconino Co., Oak Creek Canyon, near Flagstaff, 2 females, IX-6-7-1973, M. M. Sanderson, blacklight trap; NEW MEXICo: Las Cruces, 1 male, IV-21-V-2-1975, W. P. Morrison, blacklight trap; 1 male, V-15-24-1975, W. P. Morrison, blacklight trap; 1 male, V-22-27-1975, W. P. Morrison, blacklight trap; TEXAS: Lubbock, 1 male, VIII-9-14-1976, W. P. Morrison, blacklight trap; UTAH: Washington Co., Leeds Canyon, 1 female, VII-28-1965, W. J. Hanson; Cache Co., Logan, 1 male, VII-3-1968, D. W. Davis, U.V. light; Cache Co., Green Canyon, 1 female, VII-27-VIII-2-1968, W. J. Hanson, malaise trap; Grand Co., near Moab, 1 female, V-301974, Knowlton and Hanson.

Notes: Meinander described $A$. vulgaris as lacking a transverse plate and with appendages of the 9th sterum "narrow and tube-like, ending free." $\mathrm{He}$ apparently mistakenly identified the transverse plate as the terminal ends of the appendages. He also illustrated the penis as having a narrow pointed dorsal process. The "process" he illustrated is probably a lightly sclerotized connection between the penis and the ring of the 9 th sternum. In lateral view, this does 
appear to be a spine like projection of the penis, although it is actually a wide, membrane-like connection. Meinander did not illustrate the blunt dorsal process of the penis which is difficult to see without close inspection.

The sclerotized portion of the male genitalia of $A$. vulgaris is smaller than that of other species in North America, but is strongly sclerotized.

The female of $A$. vulgaris is readily identifiable by the distinctive $\mathrm{S}$-shaped appearance of the bursa copulatrix in lateral view. This can frequently be easily seen without clearing or dissecting the specimen.

The females from Utah are the largest specimens examined and represent the top limits of the measurements given above.

\section{Aleuropteryx werneri Johnson, new species}

Type: Holotype male; New Mexico; USNM.

Head (Fig. 15G): Dark brown, antennae 20-21 segmented, dark brown. Scape frequently darker than rest of antennae. Scape and pedicel twice as long as broad; most flagellar segments about 1.5 times as long as broad to twice as long as broad with median segments usually longest. Ventral spine of male pedicel about onethird to one fourth the length of segment from the distal end. Palpi brown.

Thorax: Greyish brown with blackish shoulder spots; legs brown.

Wings (Fig. 1): Dark, greyish brown. Coalescence of $R_{4+5}$ and $\mathbf{M}_{1+2}$ varies from long to short. $\mathrm{Cu}_{2}$ distinctly sinuate. Length of fore wing $2.2-3.5 \mathrm{~mm}$, hind wing $1.9-2.7 \mathrm{~mm}$.

Male genitalia (Fig. 15A-C): Ring of 9th sternum broad, longitudinally folded dorsally. Apophyses of 9th sternum rather short. Apically, the 9th sternum with a slight incision in lateral view caused by a dorsal and a ventral ridge running across it caudally. A pair of small spine-like processes dorso-laterally. A pair of flattened, upward directed processes situated medially and anteriorly to small spines.

Appendages of 9th sternum membranous, attached apically to transverse plate and with group of setae at point of attachment. Transverse plate formed of 2 curved processes joined ventrally to form a long ventral spine and with a pair of caudo-lateral projections just dorsal to where the 2 processes join. Penis ending 


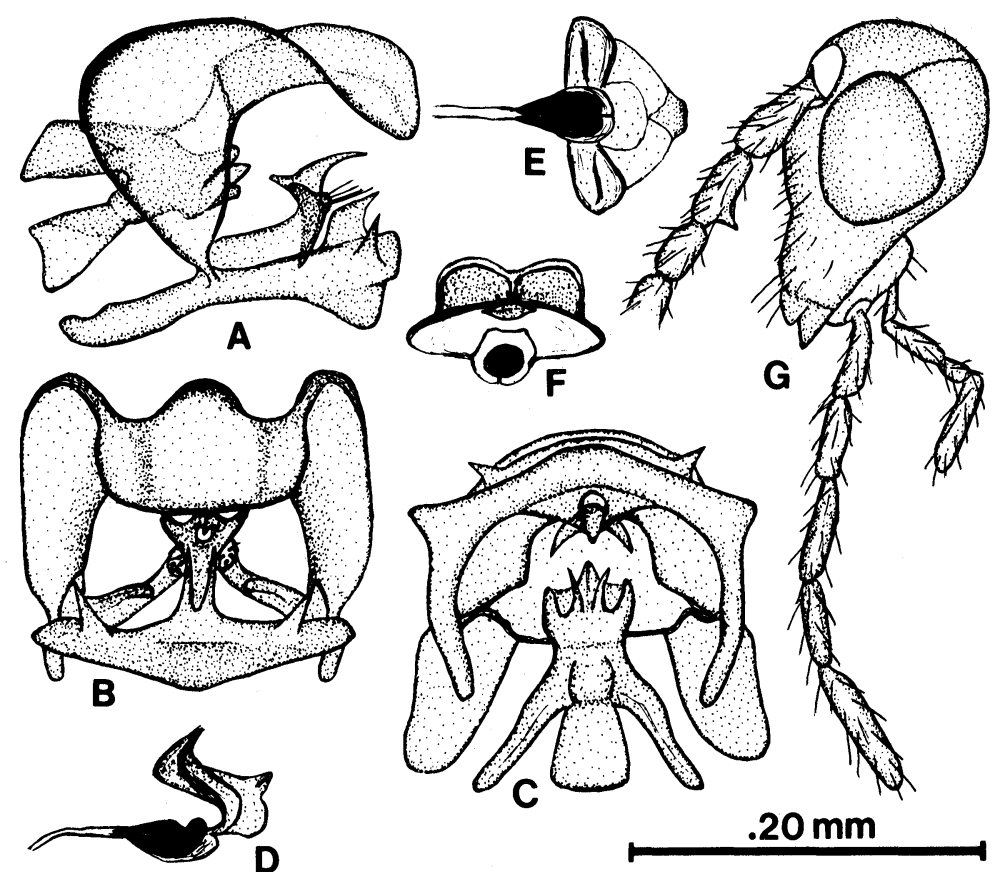

Figure 15. Aleuropteryx werneri. A. Male genitalia, lateral view. B. Male genitalia, caudal view. C. Male genitalia, ventral view. D. Female genitalia, lateral view. E. Female genitalia, ventral view. F. Female genitalia, caudal view. G. Male head, lateral view.

posteriorly in 5 processes: a pair of ventro-lateral, dorsally curved, processes; a pair of laterally flattened processes originating medially to first 2 processes; a more or less central cone-like process with a duct. Ectoprocts weakly sclerotized.

Female genitalia (Fig. 15D-F): A well sclerotized subgenital plate present. Bursa copulatrix with well sclerotized part curved upward apically in lateral view. A pair of large, dorso-lateral, transverse, sclerotized structures present; distinctive in lateral view. A tooth-like posterior projection dorso-caudal to bursa copulatrix. Immature stages unknown.

Holotype male: NEW MEXICO: Las Cruces, VII-28-VIII-3-1975, W. P. Morrison, blacklight trap.

Paratypes: NEW MEXICO: 73 males 33 females, Las Cruces, W. P. Morrison, light trap, following dates: 1 female, X-9-1974; 3 males, 
IV-21-V-2-1975; 25 males 13 females, V-10-25-1975; 2 males 2 females, VI-10-20-1975; 3 males 1 female, VI-21-27-1975; 2 males 1 female, VII-22-27-1975; 11 males 2 females, VII-28-VIII-3-1975; 10 males 10 females, VIII-1-7-1975; 17 males 3 females, VIII-8-20-1975. Deposited USNM, AUTH; ARIZ.

Notes: There is a female from Idaho (Craters of the Moon National Monument, VII-7-1964; D. S. Horning, Jr.) which may be A. werneri.

This species is related to $A$. cupressi Meinander but differs in the shape of the 9th sternum with $A$. cupressi having a median caudal projection lacking in $A$. werneri. There are other differences, but this is the most obvious one. The females apparently are very similar.

This species is dedicated to Floyd G. Werner, who provided many specimens for this work.

\section{Subfamily Coniopteryginae Enderlein, 1905}

Coniopteryginae Enderlein, 1905:225. Type: Coniopteryx Curtis.

Head capsule in lateral view not higher than broad or only slightly higher than broad. Galea one-segmented.

Besides a possible basal cross-vein, one radio-medial cross-vein in fore wing. No setae on $\mathrm{M}$. In hind wing, $\mathrm{M}$ and $\mathrm{Cu}_{1}$ not running closer together than are other veins.

No plicaturae present on abdominal segments. Wax glands in transverse bands on terga and in two areas laterally on sterna. Eighth segment weakly sclerotized. Ninth and tenth terga fused in all North American species.

Antennae of larvae about twice as long as labial palpi. Jaws basally broad and not projecting from beneath labrum.

This subfamily contains eight genera, four of which occur within the area of this present work.

\section{Key to genera}

1. $\mathrm{M}$ of hind wing unforked $\ldots \ldots \ldots \ldots \ldots \ldots$ Coniopteryx

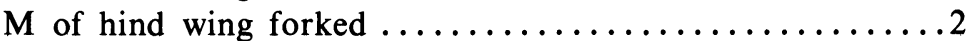

2. Cross-vein $\mathrm{m}-\mathrm{cu}_{1}$ of both wings oblique, usually striking poste-

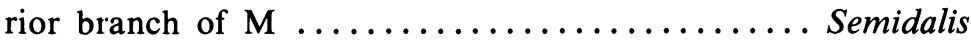
Cross-vein $\mathrm{m}$ - $\mathrm{cu}_{1}$, at least in fore wing, striking longitudinal veins at right angles and always stem of $\mathrm{M} \ldots \ldots \ldots \ldots \ldots \ldots$ 
3. Hind wing reduced or not reduced. If not reduced, then Rs forking off from $\mathrm{R}$ in middle of wing........... Conwentzia Hind wing not reduced. Rs forking off from $\mathrm{R}$ basally of middle of wing $\ldots \ldots \ldots \ldots \ldots \ldots \ldots \ldots \ldots$. Parasemidalis

\section{ReFERENCES Cited}

Arrow, G. J. 1917. The life-history of Conwentzia psociformis. Entomol. Monthly mag. s3:254-257.

Banks, N. 1906. A revision of the Nearctic Coniopterygidae. Proc. Entomol. Soc. Wash. 8:77-86.

Burmeister, H. C. C. 1839. Neuroptera. In: Handbuch der Entomologie 2:7561050. Berlin.

Collyer, C. 1951. The separation of Conwentzia pineticola End. from Conwentzia psociformis (Curt.) and notes on their biology. Bull. Entomol. Res. 42:555564.

Curtis, J. 1834. British Entomology 11:pl. 528. London.

Enderlein, G. 1905. Klassifikation der Neuropteran-Familie Coniopterygidae. Zool. Anz. 29:225-227.

Flint, O. S. 1974. Cooperative Economic Insect Rep. 24(35):703 (PPQ).

HenRy, T. J. 1974. Cooperative Economic Insect Rep. 24(33):659 (PPQ).

1976. Aleuropteryx juniperi: A European scale predator, established in North America (Neuroptera: Coniopterygidae). Proc. Entomol. Soc. Wash. 78(2): 195-201.

Johnson, V. 1976. A new genus and species of Coniopterygidae (Neuroptera) from New Mexico. Psyche 83:192-195.

Klapalek, F. 1894. Is Aleuropteryx lutea Low, identical with Coniopteryx lutea Wallg.? Entomol. Monthly Mag. 5:121-122.

Low, F. 1885. Beitrag zur Kenntnis der Coniopterygiden. Sitzungsber. Kaiserl. Akad. Wiss. Mathem.-Nat. Classe 91:73-89.

Meinander, M. 1972. A revision of the family Coniopterygidae (Planipennia). Acta Zool. Fennica 136:1-357.

1974. Coniopterygidae from Western North America. Entomol. Scand. 5:217-232.

1975. Coniopterygidae from North America (Neuroptera). Notulae Entomol. 55:28-32.

Muma, M. H. 1967. Biological notes on Coniopteryx vicina (Neuroptera: Coniopterygidae). Florida Entomol. 50:285-293.

Онм, Р. 1968. Vorlaufige Beschreibung einer neuen europaischen Aleuropteryzart (Neuroptera, Coniopterygidae). Entomol. Nachrchtenbl. 15:12-15.

Quayle, H. J. 1912. Red spiders and mites of citrus trees. Univ. California Agric. Exper. Sta. Bull. 234:481-530.

TJeDER, B. 1956. Neuroptera. In: Tuxen, S. L. (ed.), Taxonomist's glossary of genitalia in insects:76-83. Copenhagen.

1970. Neuroptera. In: Tuxen, S. L. (ed.), Taxonomist's glossary of genitalia in insects:89-99. Copenhagen. 
WARD, L. K. 1970. Aleuropteryx juniperi Ohm (Neur. Coniopterygidae) new to Britain feeding on Carulaspis juniperi Bouche (Hem. Diaspididae). Entomol. Monthly Mag. 106:74-78.

Wheeler, A. G. JR. 1980. First United States record of Aleuropteryx simillima, a predator of scale insects on ornamental juniper (Neuroptera: Coniopterygidae). The Southwestern Entomologist 5(1):51-52.

Wiтнусомве, C. L. 1922. Parasemidalis annae End., a coniopterygid new to Britain, with notes on other British Coniopterygidae. Entomologist 55:169-172. 1923. Notes on the biology of some British Neuroptera (Planipennia). Trans. Entomol. Soc. London 1922:501-594.

1924. Notes on the economic value of the Neuroptera with special reference to the Coniopterygidae. Ann. Appl. Biol. 11:112-125. 

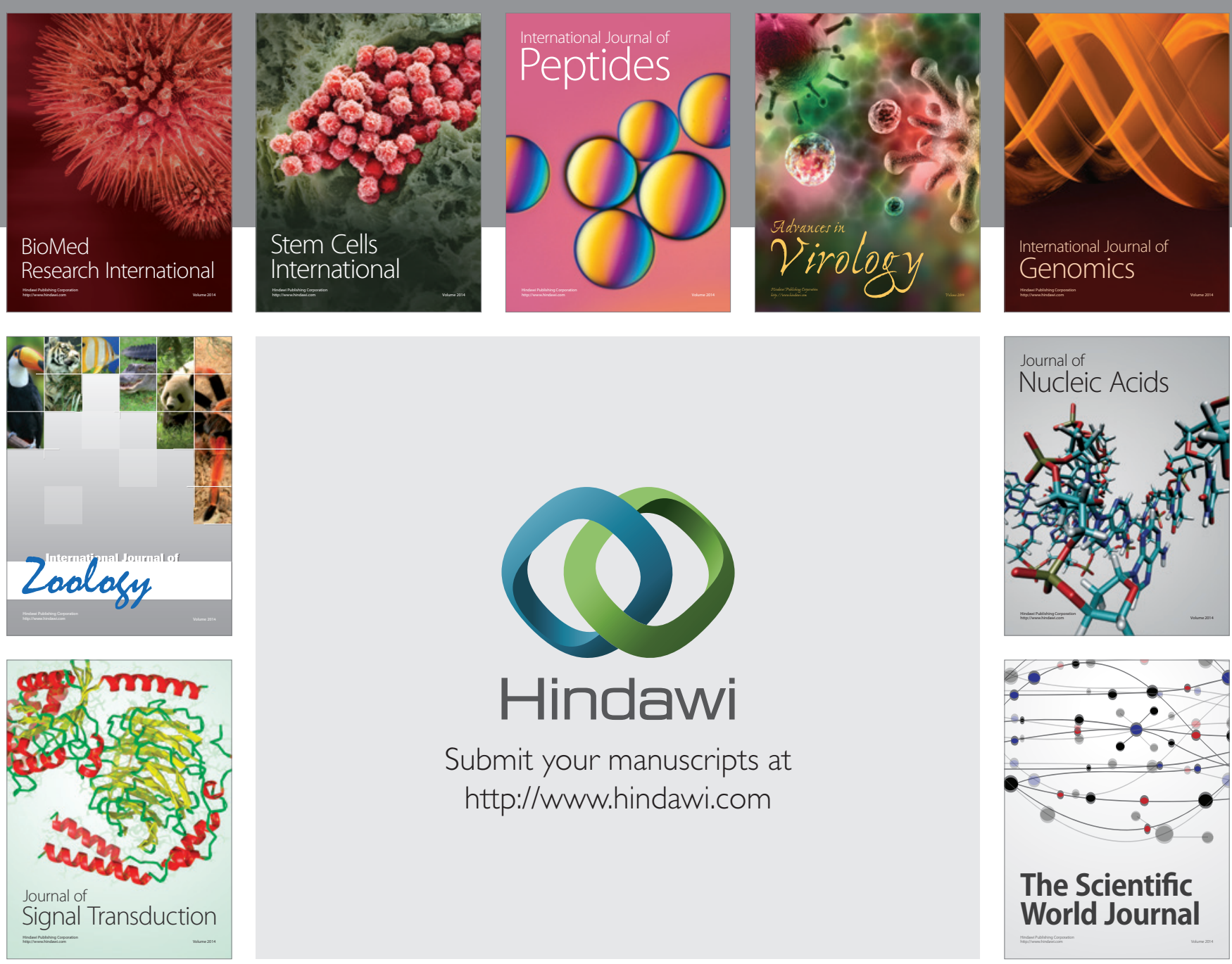

Submit your manuscripts at

http://www.hindawi.com
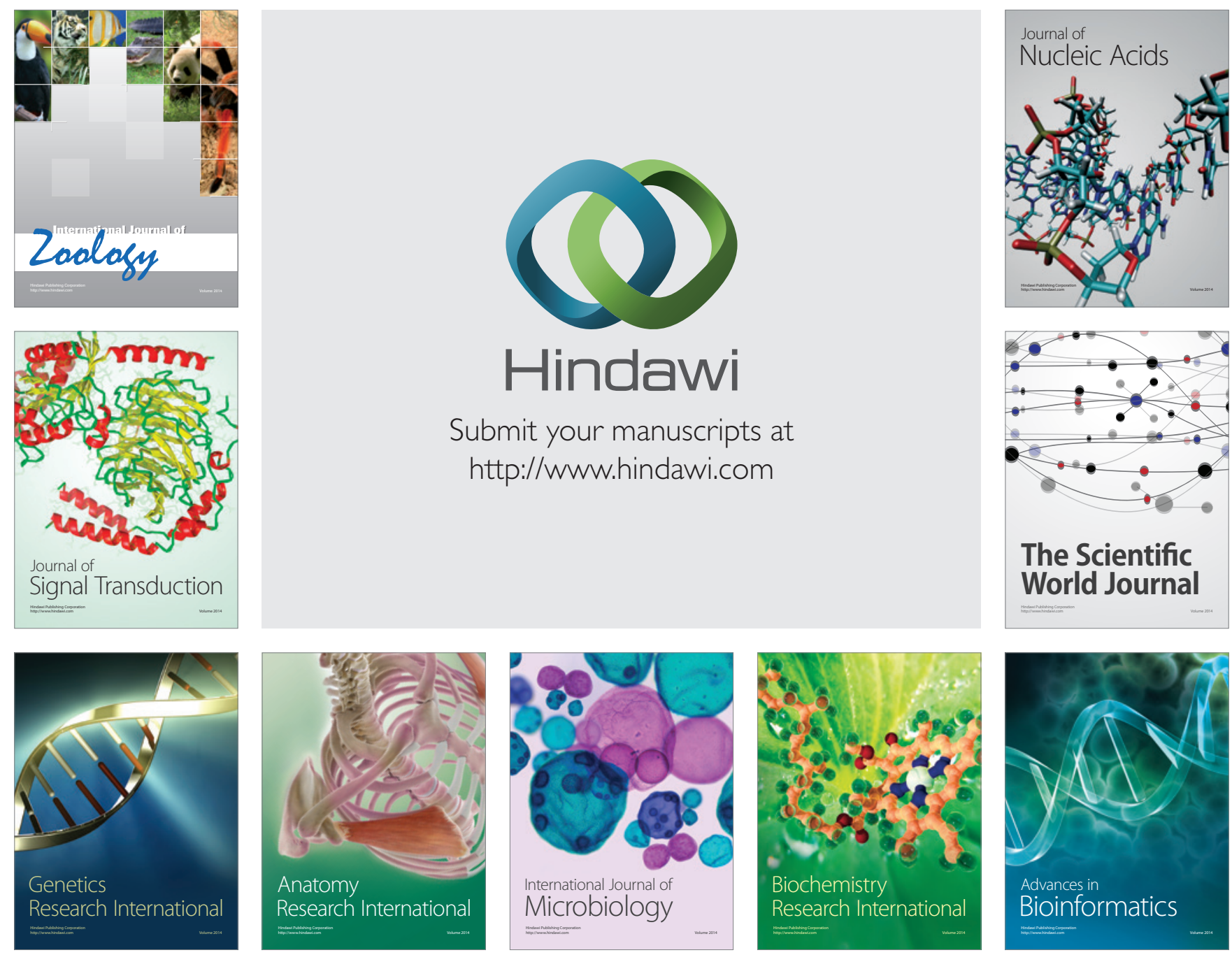

The Scientific World Journal
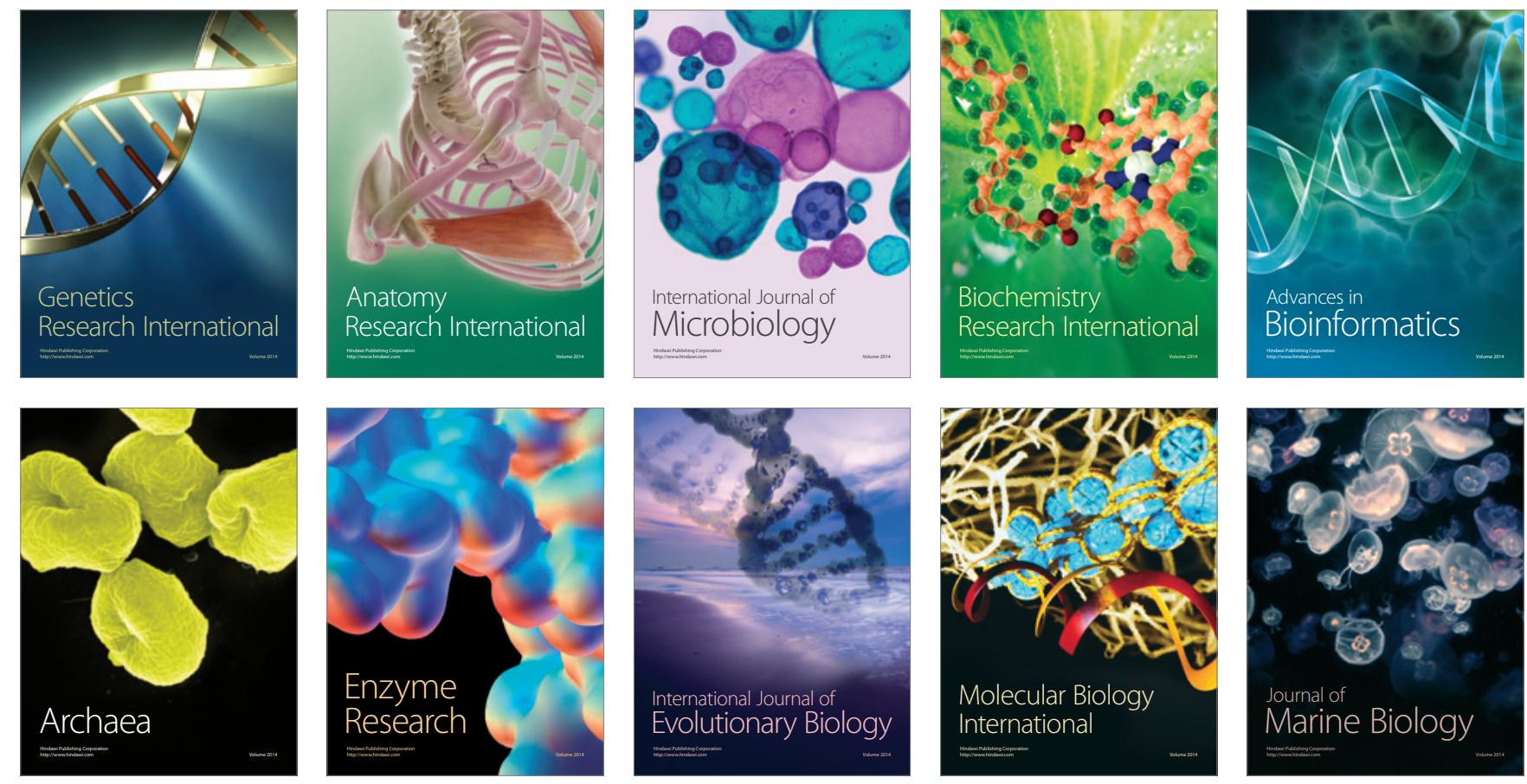